\title{
HVMANITAS
}

\section{Un pasaje importante para el estudio de los ejercicios físicos en los Tratados médicos hipocráticos}
Autor(es):
López Férez, Juan Antonio
Publicado por:
Faculdade de Letras da Universidade de Coimbra, Instituto de Estudos Clássicos
URL persistente:
URI:http://hdl.handle.net/10316.2/27955
DOI:
DOI:http://dx.doi.org/10.14195/2183-1718_61_14
Accessed :
26-Apr-2023 07:48:55

A navegação consulta e descarregamento dos títulos inseridos nas Bibliotecas Digitais UC Digitalis, UC Pombalina e UC Impactum, pressupõem a aceitação plena e sem reservas dos Termos e Condições de Uso destas Bibliotecas Digitais, disponíveis em https://digitalis.uc.pt/pt-pt/termos.

Conforme exposto nos referidos Termos e Condições de Uso, o descarregamento de títulos de acesso restrito requer uma licença válida de autorização devendo o utilizador aceder ao(s) documento(s) a partir de um endereço de IP da instituição detentora da supramencionada licença.

Ao utilizador é apenas permitido o descarregamento para uso pessoal, pelo que o emprego do(s) título(s) descarregado(s) para outro fim, designadamente comercial, carece de autorização do respetivo autor ou editor da obra.

Na medida em que todas as obras da UC Digitalis se encontram protegidas pelo Código do Direito de Autor e Direitos Conexos e demais legislação aplicável, toda a cópia, parcial ou total, deste documento, nos casos em que é legalmente admitida, deverá conter ou fazer-se acompanhar por este aviso. 
humanitas

\section{Vol. LXI}

IMPRENSA DA UNIVERSIDADE DE COIMBRA

COIMBRA UNIVERSITY PRESS 


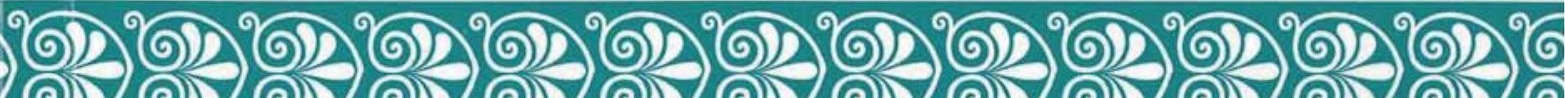

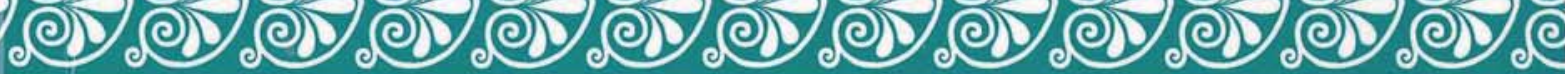

Vol. LXI 


\title{
UN PASAJE IMPORTANTE PARA EL ESTUDIO DE LOS EJERCICIOS FÍSICOS EN LOS TRATADOS MÉDICOS HIPOCRÁTICOS*
}

\author{
Juan Antonio López Férez \\ Universidad Nacional de Educación a Distancia (UNED), Madrid \\ jalferez@flog.uned.es
}

\section{Resumen}

Análisis de un pasaje hipocrático (Sobre la dieta, 3. 70-85) importante para el estudio de los ejercicios físicos.

Palabras clave: Texto hipocrático estudio ejercicios físicos.

\section{Abstract}

Analysis of one Hippocratic text (On diet, 3. 70-85) important for the study of physical exercices.

Keywords: Hippocratic text study physical exercices.

A mis alumnos del Doctorado de la Universidad de León: Ciencias de la actividad física y del deporte.

\section{Los Tratados médicos hipocráticos (A modo de prólogo)}

Internacionalmente se llama Corpus Hippocraticum (en lo sucesivo $\mathrm{CH}$ ) a los tratados de contenido esencialmente médico que nos han llegado

* Terminado dentro del Proyecto HUM2006-08548 de la Dirección General de Investigación (Ministerio de Educación y Ciencia) 
atribuidos a Hipócrates y a su escuela desde la Antigüedad ${ }^{1}$. Tal Corpus, conocido también como Colección hipocrática o Tratados médicos hipocráticos, es la primera compilación de textos científicos que nos ha transmitido la Antigüedad clásica grecorromana. La mayor parte de los escritos que la componen fue escrita entre 420 y 350 a.C.

Hipócrates vivió aproximadamente entre 460 y 370 a.C., estudió y se formó junto a su padre, Heraclides, médico también, y estuvo en relación con ilustres hombres de su tiempo, entre ellos el famoso Heródico de Selimbria del que hablaremos. Viajó bastante y ejerció la medicina en diversos puntos de Grecia. Sólo con lo que nos dicen Platón (Fedro y Protágoras, especialmente) y Aristóteles (Política, ante todo) hay suficiente para considerar a Hipócrates como el médico más sobresaliente de su época y de trascendental importancia en los planos histórico y cultural. Precisamente, un testimonio que ha hecho correr mucha tinta es el de Platón ${ }^{2}$, cuando se afirma que, a juicio de Hipócrates, no es posible entender, ni digna ni adecuadamente, la naturaleza del cuerpo sin comprender la naturaleza del todo.

Los estudiosos no logran ponerse de acuerdo en qué libros remontan al propio Hipócrates. Se le suelen atribuir entre cuatro y ocho tratados (Sobre las articulaciones, Sobre las fracturas, Pronóstico, Epidemias 1 y 3,...). No puedo entrar en los problemas cronológicos, pero sí conviene decir que un grupo importante de tratados es anterior al 400 a.C.; otro, de comienzos del siglo IV; y, luego, hay escritos posteriores, hasta del siglo II d.C. Es decir, entre los primeros tratados y los últimos hay un lapso de casi siete siglos.

Diré sólo unas palabras sobre la relación de filosofía y medicina dentro del $\mathrm{CH}$. Puede decirse que los médicos hipocráticos dependen en buena medida de las lucubraciones filosóficas de los Presocráticos, entendido este término en sentido amplio, ya que algunos de ellos no son anteriores, sino contemporáneos de Sócrates. De hecho la influencia de tales pensadores (de modo especial,

${ }^{1}$ La edición bilingüe (griego-francesa) de E.Littré, en diez volúmenes, sigue siendo la más completa hasta hoy: recoge cincuenta y ocho escritos distribuidos en setenta y tres libros. De acuerdo con las normas internacionales, cito por esa edición (ateniéndome a las indicaciones de esta revista, en primer lugar, aparece la abreviatura en latín; luego, el libro y capítulo (o simplemente, capítulo), o libro, sección y capítulo; después, el tomo de Littré, la página, y, en su caso, la línea. Por ejemplo: Morb. 2. 72. 7. 110.11; Salubr.7. 6. 82.7; Epid. 6.3.18. 5. 302.2).

Una introducción general al $\mathrm{CH}$ puede encontrarse, por ejemplo, en mi trabajo publicado en la Historia de la literatura griega. Véase la bibliografía.

${ }^{2}$ Phdr. 270 b-d. 
Pitágoras, Heráclito, Empédocles, Anaxágoras, Demócrito, Diógenes de Apolonia) es patente o probable en algunos escritos hipocráticos.

Concretamente, en el tratado Sobre la dieta, del que me ocuparé a continuación, encontramos varios postulados de origen filosófico: la teoría de los contrarios, bien establecida desde Alcmeón y Heráclito, notoria en bastantes tratados del $\mathrm{CH}$ y fundamental para explicar la etiología de las enfermedades. En ella, destacan las cuatro cualidades básicas: frío/ calor, seco/húmedo; el principio conocido por la expresión latina, contraria contrariis curantur ("los contrarios se curan con los remedios contrarios"); la importancia de la dieta para la salud humana, tal como habían sostenido los pitagóricos y Demócrito; la función esencial del pneuma, que puede remontar a Diógenes de Apolonia en líneas generales; etc.

\section{Sobre la dieta. Aspectos generales}

El autor de este extenso tratado, fechable a fines del $\mathrm{V}$ o principios del IV a.C., comienza diciendo que nadie ha hablado en serio sobre tal tema antes que él, y que, para estudiar correctamente la dieta humana, hay que conocer la naturaleza del hombre en general. La salud se consigue mediante el adecuado equilibrio entre alimentos y ejercicios ${ }^{3}$; todos los seres, y entre ellos el hombre, están compuestos de agua y fuego.

Un esquema del contenido puede ser el siguiente. El libro 1 trata del desarrollo del embrión, la generación de gemelos, el sexo y la composición del cuerpo: abunda en postulados tomados de Empédocles y, algo menos, de Heráclito; el 2 estudia las acciones ejercidas sobre el cuerpo humano por los lugares, vientos, comidas, bebidas, baños y ejercicios corporales. Ofrece información muy pertinente sobre la alimentación de aquellos momentos. Entre otros manjares aparecen la leche, trigo, cebada, espelta, pan duro y tierno, leguminosas, carnes, peces, crustáceos, huevos, queso, bebidas, miel, frutas; el 3 distingue varias dietas según la profesión y régimen de vida: examina el predominio de los alimentos sobre los ejercicios (la llamada plétora o plenitud), y de los ejercicios sobre los alimentos (la

${ }^{3}$ Es opinión generalmente admitida que los pitagóricos fundaron la dietética a partir de la segunda mitad del VI a. C. Por diversas noticias que nos han llegado sabemos que buscaban el equilibrio, la salud del cuerpo y del alma; asimismo, se interesaron por la relación que debía mantenerse entre alimentos y descanso. Fuentes tardías nos informan de que los seguidores de tales teorías solían reunirse al amanecer para el estudio, y, a continuación, practicaban diversos ejercicios gimnásticos. 
vacuidad); por último, el 4, llamado Sobre los ensueños, se ocupa de la importancia de los signos que se presentan durante el sueño. En general, los sueños son interpretados como signos de perturbación corporal.

Sobre la dieta es una de las obras mejor estructuradas dentro de los Tratados hipocráticos. El pensamiento del autor es coherente, y la doctrina de los dos elementos (agua-fuego) es evidente por doquier. Su estilo es cuidado, con buen conocimiento de las normas retóricas y de los periodos largos, aunque no faltan contrastes violentos, repeticiones monótonas y aspereza sintáctica, notas típicas de la literatura arcaica.

Para el estudioso de los ejercicios físicos en la Antigüedad puede ser de utilidad la lectura de un pasaje del tratado Sobre la dieta ${ }^{4}$, concretamente el libro 3, capítulos 70-85, como veremos más abajo. Conviene decir que, algo antes, precisamente en el capítulo 69, el autor hipocrático da una serie de recomendaciones a quienes pueden desentenderse de las demás cosas y dedicarse a cuidar de su salud; para ellos ha descubierto una dieta que se aproxima lo más posible al máximo grado de verdad. Es un hallazgo que ha hecho, hermoso para él y útil para quienes lo aprendan. Lo cree de gran valor y sostiene que ninguno de los antepasados se ocupó nunca de comprender esas cosas. Su aportación consiste en un diagnóstico previo al enfermar; se ocupa de lo que les sucede a los cuerpos si el alimento prevalece sobre los ejercicios, o si los ejercicios dominan a los alimentos, o si ambos están equilibrados. El autor insiste en que las enfermedades se producen cuando predomina uno de esos elementos; en cambio, cuando hay equilibrio

${ }^{4}$ Todas las traducciones que ofrezco en este estudio son mías, bastante literales. Una versión española de todo el tratado puede encontrarse en Tratados hipocráticos (1986), 3. Madrid: Gredos, 19-116.

Para este tratado, me atengo a Joly, R. (1984), Du régime. Berlín: Corpus Medicorum Graecorum 1.2.4 (bilingüe: griego-francés). También he consultado, entre otras, la edición, asimismo bilingüe, del mismo autor aparecida en (1967), París. Collection des universités de France, y la de Jones, W. H. S. 1967 (ésta, reimpresión de la primera, publicada en 1931), Regimen, en Hippocrates. 4. Londres-Cambridge (Massachusetts), 224-447 (bilingüe: griego-inglesa). Por lo demás, sigo los textos ofrecidos por el TLG (32; año 2000) (Thesaurus Linguae Graecae), seleccionando los más relevantes.

Los puntos suspensivos entre corchetes [...] son míos, señal de que he omitido elementos del texto irrelevantes para nuestro propósito.

(En atención al lector que no sepa griego, transcribo los términos y pasajes esenciales) 
Un pasaje importante para el estudio de los ejercicios físicos

entre ellos, llega la salud. Va a tratar de esos casos, indicando cómo son y cómo se manifiestan en personas que parecen gozar de salud, comen con gusto, pueden hacer ejercicios y están bien de cuerpo y de color.

\section{Sobre la dieta, 3. 70-85. Traducción y notas}

$70^{5}$. Las narices se llenan sin motivo evidente tras la comida y el sueño ${ }^{6}$, y parecen estar llenas, pero no moquean nada. Mas cuando ( $s c$. las personas) empiezan a pasear $^{7}$ por la madrugada ${ }^{8}$ y a hacer gimnasia ${ }^{9}$,

${ }^{5}$ En los capítulos 70-78 los alimentos dominan a los ejercicios. El médico, pues, recomendará disminuir los primeros y aumentar los segundos. Esa será la tónica general, como veremos.

En nuestro comentario destacamos, ante todo, los aspectos relacionados con los ejercicios físicos, o que tienen, al menos, cierta conexión con ellos.

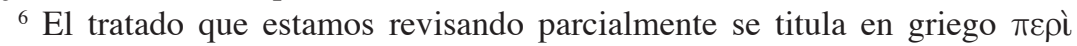
Suaítns (perì diaítess); en latín, de victu, entendiendo victus en un sentido amplio, equivalente a "tipo de vida". Efectivamente, la dieta (Síaıta, díaita) a la que se dedican varios escritos hipocráticos (Sobre la dieta, Sobre la dieta sana, Sobre la dieta en las enfermedades agudas), comprendía, como leeremos, no sólo normas referentes a las alimentación (comidas y bebidas) sino también numerosas pautas relativas a ejercicios corporales, higiene (baños, por ejemplo), horas de sueño y vigilia, relaciones sexuales, etc.; todo ello de acuerdo con la edad, profesión, sexo, país, aguas, aires, etc. Una norma varias veces recomendada es la de guardar el debido equilibrio entre alimentos ingeridos y ejercicios realizados.

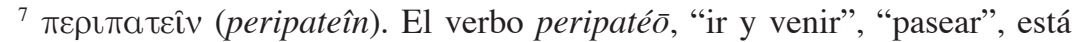
registrado 51 veces en el $\mathrm{CH}$, que es la primera colección que lo recoge; después, aparecerá en Aristófanes. Véase la nota 18.

Tendremos ocasión de ver algunos ejemplos en que el autor de Sobre la dieta da distintas recomendaciones sobre el paseo: por la sombra, por el sol, por la mañana, etc. Insistiremos en un punto esencial: el paseo es distinto del ejercicio físico o gimnástico, según los autores hipocráticos, como comprobaremos más adelante.

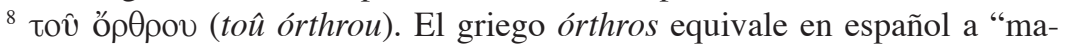
drugada", "amanecer", "alba", es decir, el tiempo que transcurre desde las primeras luces del día hasta la salida del sol. Término que aparece ya en el siglo VIII (Hesíodo), lo encontramos 13 veces en el $\mathrm{CH}$ (de ellas 4 en Vict.). El adjetivo correspondiente, órthrios, "propio del amanecer", está registrado en 16 ocasiones dentro del $\mathrm{CH}$ (15 en Vict.). Así, pues, el autor del tratado que estamos revisando ofrece un interés especial por indicar tal momento del día.

${ }^{9} \gamma 0 \mu v \alpha ́ \zeta c \sigma \theta a u$ (gymnázesthai). El verbo gymnázo, "hacer ejercicios gimnásticos", lo tenemos 32 veces en el $\mathrm{CH}$, (6 en Vict.) usado normalmente en voz media 
entonces moquean y escupen. Avanzando el tiempo, los párpados también se ponen pesados, y como una comezón ocupa la frente, y tienen menos gana de alimentos y pueden beber menos, y les sobrevienen palideces; por tanto, surgen catarros o fiebres con escalofríos, en el lugar adonde haya sido removida la plenitud. A cualquier cosa que se encuentre haciendo en este momento se le echa la culpa, pero eso recibe la culpa no siendo cul-

intransitiva o voz pasiva; aparece en el siglo VI (Teognis), y se generaliza en el V: Esquilo, Heródoto, Tucídides, etc. El $\mathrm{CH}$, pues, figura entre los primeros en registrarlo.

Selecciono unos pocos ejemplos para hacer notar la diferencia respecto a "pasear". Efectivamente, en una clase de hipocondría se nos dice: "Que no beba vino, sino, especialmente, agua. Y, si no, vino aguado. Que no haga ejercicio

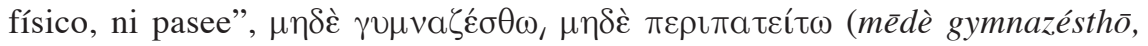
médè peripateítō), Morb. 2. 72. 7. 110.11; y, con referencia a otro enfermo de la misma afección: "Que se dé baños fríos en verano y primavera, y se dé unciones en otoño e invierno, y que camine y haga unos pocos ejercicios gimnásticos",

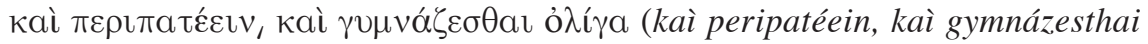
olíga), Morb. 2. 66. 7. 100.22; en un caso de enfermedad negra se recomienda suero, alimentos fríos y relajantes, evacuaciones por arriba, sacar sangre del brazo, purgantes, y "que se guarde del sol, y no haga mucho ejercicio físico,

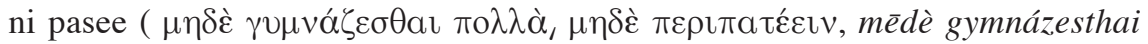
pollá, mèdè peripatéein), ni coma nada agrio ni salado", Morb. 2. 73. 7. 112.9; recomendación para un enfermo de tisis: "Ése es preciso que beba heléboro y agua de lentejas, y que coma bien, y se abstenga de cosas agrias [...] y haga algunos

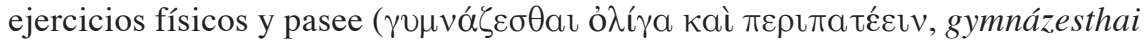
olíga kaì peripatéein), y use vomitivos tras los alimentos y se abstenga del coito", Morb. 2. 49.7. 76. 5; y, finalmente, la siguiente admonición: "Es preciso

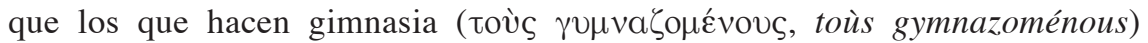
corran y luchen en invierno, y que luchen poco en verano y no corran, pero que paseen mucho al fresco", Salubr.7. 6. 82.7 (en este pasaje se advierte que "correr" (tréchein) es algo distinto de "pasear" (peripateîn). Insistiremos en tal punto). 
Un pasaje importante para el estudio de los ejercicios físicos

pable. Pues en ése los alimentos dominan a los ejercicios ${ }^{10}$ y la plenitud ${ }^{11}$, acumulada poco a poco, lo lleva a la enfermedad; pero no hay que dejarse llevar hasta tal punto, sino, cuando conozca los primeros signos, saber que los alimentos dominan a los ejercicios y que la plenitud se ha acumulado poco a poco. Pues la mucosidad y la saliva son crisis $^{12}$ de la plenitud. Precisamente, encontrándose tranquilo el cuerpo, bloquean los pasos de la respiración ${ }^{13}$,

${ }^{10} \mathrm{El}$ hipocrático ve la salud como un equilibrio de elementos, tanto externos

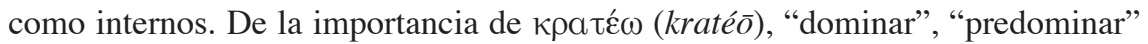
en el tratado que estamos revisando nos da noticia el número de apariciones: $\mathrm{CH}$ (145), Vict. (39); es decir, el escrito del que hablamos contiene casi el $30 \%$ de los ejemplos hipocráticos. En general, se considera malo el predominio, tanto de los alimentos como de los ejercicios físicos. El médico se ocupará de buscar un equilibrio, una armonía, entre ambos.

En el CH, róvos (pónos) es un sustantivo frecuente: 498 ejemplos. El campo semántico es amplio: "trabajo", "fatiga", "sufrimiento", "ejercicio".

${ }^{11}$ En virtud del pensamiento polar, la oposición de contrarios, el hipocrático piensa en dos estados contrapuestos por lo que se refiere al cuerpo humano: la plenitud o plétora ( $\pi \lambda \eta \sigma \mu o v \eta ́$, plesmonē) y la vacuidad ( $\kappa \dot{\varepsilon} v \omega \sigma \iota \varsigma$, kénōsis).

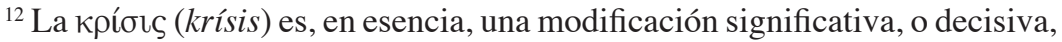
en el curso de una enfermedad. Momento tan especial se manifiesta por medio de signos externos: sudor, orina, deposiciones, etc.

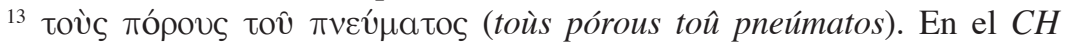

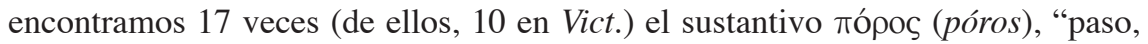
camino"; de los diversos pasajes puede deducirse que el hipocrático suponía que el cuerpo humano está atravesado por una serie de pasos por los que se eliminan o cambian de lugar ciertos elementos internos. En Vict. se habla, incluso, dos veces, de poros del alma: cf. Vict. 1. 35. 6. 514.26.

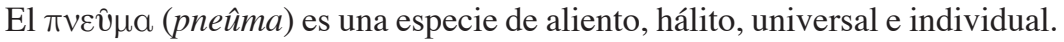
El CH contiene un tratado cuyo título latino es de flatibus (Sobre los flatos), de fines del V o comienzos del IV a.C., en el que se intenta demostrar que los flatos (soplo o aire que penetra en el cuerpo humano desde el exterior o que se halla ya en el interior del mismo) son la causa de todas las enfermedades. Dentro del $\mathrm{CH}$, pneûma es un vocablo polisémico: "soplo", "viento", "respiración", "aliento"; tanto puede referirse al viento exterior como al aire contenido en el cuerpo humano; sus funciones son varias: alimentar, impulsar, refrescar, vivificar. 
siendo mucha la plenitud en el interior. Pero calentándose a causa del ejercicio $^{14}$, $\left(s c\right.$. el cuerpo), responde adelgazando ${ }^{15}$.

A tal paciente hay que cuidarlo del siguiente modo. Que practique los ejercicios físicos acostumbrados, sin fatigarse ${ }^{16}, y$, tras bañarse en agua

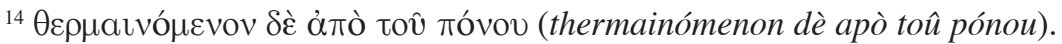
Veremos en otros ejemplos la atención prestada por el médico al calentamiento del cuerpo; es opinión general que, con el calor proporcionado por el ejercicio físico, el cuerpo adelgaza.

Los estudiosos hablan de oposiciones binarias, polares, propias del pensamiento griego arcaico (derecha / izquierda, luz/oscuridad, etc.) en las que un elemento resulta ser el positivo y el otro, el negativo; pero, asimismo, insisten en que ni "caliente" ni "frío", ni "seco" ni "húmedo" alcanzaron un sentido claramente positivo ni negativo en ese estadio del pensamiento griego en que abundan teorías contrarias. Así, si remonta a Parménides la teoría de que la mujer es más caliente que el hombre, Empédocles sostiene lo contrario: el hombre es más caliente que la mujer.

Entre los médicos hipocráticos hallamos varios reflejos de esas lucubraciones de los Presocráticos. En efecto, en una secuencia del tratado que analizamos, leemos: "En general, los varones son más calientes y más secos; las mujeres, más húmedas y más frías, por lo siguiente. Desde el comienzo ambos disfrutaron de tales cualidades y crecían por obra de ellas, pero, ya nacidos, los varones siguen regímenes de vida laboriosos, de suerte que se calientan y resecan, mientras que las mujeres siguen un régimen especialmente húmedo e indolente y cada mes tienen una purgación del calor que procede del cuerpo", Vict. 1. 34. 6. 512. Por el contrario, en otro tratado leemos: "La mujer tiene la sangre más caliente, y por ello es más caliente que el hombre", Mul. 1. 1. 8. 12.

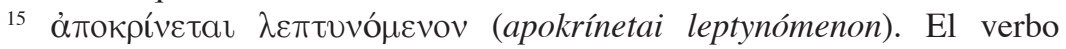
$\lambda \varepsilon \pi \tau u ́ v \omega$ (leptýnō), "adelgazar, hacer adelgazar", en una innovación del CH (81 apariciones). Contra lo que opinan Joly y otros, pienso que el sujeto es el cuerpo (elíptico, pero mencionado poco antes), y no el humor.

${ }^{16}$ Dos indicadores nos muestran la capacidad de observación del médico hipocrático y la gran experiencia adquirida a lo largo de su aprendizaje: recomienda que determinado paciente insista "en los ejercicios gimnásticos acostumbrados"

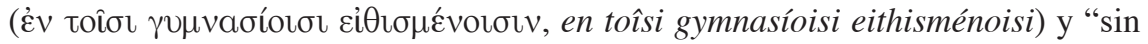

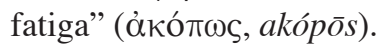

El verbo ė $\theta i \zeta \zeta \omega$ (ethízo), "acostumbrar", casi siempre en voz media (o pasiva) en el $\mathrm{CH}$, nace en el siglo V: Hipócrates, Tucídides y Aristófanes ofrecen los primeros ejemplos. Bastante usado en los tratados hipocráticos es el participio de perfecto, eithisménos (-on), "el que tiene una costumbre", "el acostumbrado a algo", y, en neutro, "lo acostumbrado". Para el médico siempre es una garantía conocer, en cada enfermo, las acciones acostumbradas (comidas, ejercicios, 
Un pasaje importante para el estudio de los ejercicios físicos

caliente, alimentarlo con toda clase de productos y hacerle vomitar inme-

sueños, deposiciones, etc.); recomendará al paciente que haga lo que tenga por costumbre, si hasta entonces le ha ido bien.

Conviene subrayar también el adverbio akópōs, pues es la primera vez que aparece en la literatura griega y sólo en esta ocasión dentro del $\mathrm{CH}$; en todo caso, el mensaje de hacer ejercicio "sin fatiga", o, quizá, "sin llegar a las agujetas" (entiéndase, la sensación de fatiga en quien lo realiza) es un hito importante en la historia de los ejercicios físicos. Cf. nota 25.

El término griego para ejercicio físico en este pasaje es gymnasíoisi (gymnásion en nominativo de singular). Este sustantivo lo contamos 52 veces en el CH (35 en Vict.) y tiene dos significados claros: "ejercicio gimnástico" o "físico", y "gimnasio", o lugar donde se realizan los ejercicios físicos. (Más indicaciones pueden obtenerse de la nota 46). Recojo unos ejemplos significativos: 1)Para quienes se interesan por la historia de los ejercicios gimnásticos he aquí una secuencia de gran importancia: "Incluso ahora, los que se ocupan de los ejercicios

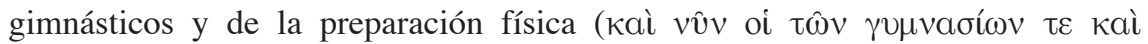

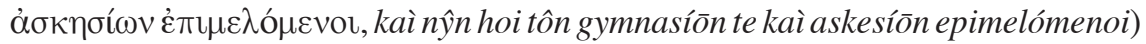
descubren siempre algo más, investigando con el mismo método qué comidas y bebidas digerirá mejor y con cuáles resultará más fuerte”, $V M$ 4. 1. 580.2; 2). En otro lugar, se recomienda andar con la pierna buena y una muleta, en vez de apoyar en el suelo la pierna enferma: "Pero si ( $s c$. el enfermo) no apoya en tierra la pierna enferma, sino que, manteniéndola en el aire, se sirve de una muleta, de ese modo la pierna sana se vuelve fuerte, pues es utilizada según la naturaleza, y, además, los

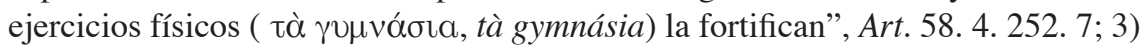
"Señal en los ejercicios físicos (en gymnasíoisi): el sudor, corriendo gota a gota, que sale como si fuera de fuentes", Epid.6. 3.1.5.292.11(Nótese la descripción casi poética del sudor copioso y a chorros, tras un esfuerzo físico notable); 4) "Los paseos después de los ejercicios gimnásticos dejan los cuerpos purgados y delgados

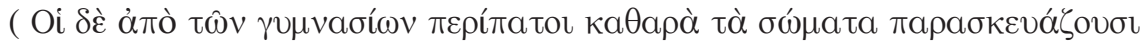

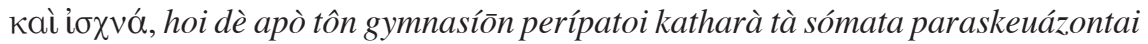
kaì ischná), pues no permiten que se recomponga la fusión de la carne que es obra

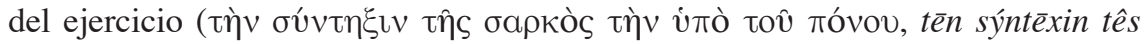
sarkòs tēn hypò toû pónou), sino que la purifican", Vict.2. 62. 6. 578.7; 5) "Dar

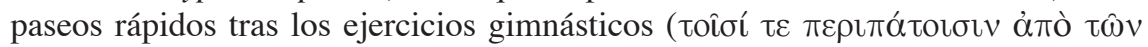

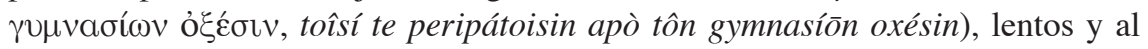
sol tras la comida, y muchos paseos de madrugada, comenzando poco a poco, avanzando a ritmo vivo y acabando con calma", Vict. 3. 68. 6. 596. 2.

En ocasiones no es recomendable el ejercicio físico. Cito dos ejemplos: a) "A cuantos se les producen dolores de las vísceras a consecuencia del ejercicio gimnástico o de cualquiera otra fatiga, a ésos les conviene reposar en ayunas", Salubr.7. 6. 84. 18; b) Tampoco es bueno el ejercicio físico cuando, en la com- 
diatamente. Después del vómito ${ }^{17}$, que se lave la boca y la garganta con vino seco para que los orificios de las venas se cierren y no sea absorbido nada de cuanto es producido por los vómitos. Luego, tras levantarse, que dé unos pocos paseos por el sol. Para el día siguiente, que practique los mismos paseos, pero ejercicios gimnásticos, menos y más ligeros que

posición de cuerpo humano, el agua es sobrepasada por el fuego: "Es preciso que quien es así se abstenga de todas las cosas, y de toda plenitud, y de ejercicios

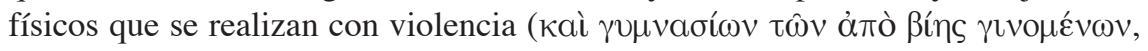
kaì gymnasíon tôn apò biés ginoménōn)", Vict. 1. 35. 6. 522.3.

En la secuencia a. hay algunas discrepancias textuales, pues una parte de los manuscritos ofrece gymnasíon y otros tienen la lectura ek gymnasiés, " a causa de la gimnasia". Precisamente gymnasié la hallamos cuatro veces en el $\mathrm{CH}$, pero aparece con frecuencia frente a otras lecciones alternativas; por lo demás ese sustantivo lo tenemos, por primera vez, en los tratados hipocráticos y en Platón.

El hipocrático, buen observador, concede gran importancia al momento preciso en que ocurren o se presentan determinadas realidades. En ciertas secuencias se habla de "en los ejercicios gimnásticos", precisión temporal o local, que en griego se construye mediante la preposición griega en seguida de dativo. Por su interés daré otro ejemplo: "Si se come la cena, y da los paseos consabidos, será más agradable de aspecto y más rápido y más activo en los ejercicios gimnásticos", Prorrh.II 4. IX 16.11.

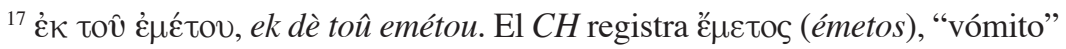
en 200 ocasiones. El término surge en el siglo V a. C. Otro autor que lo emplea es Heródoto (1), en 2.77.2, cuando nos dice que los egipcios "toman purgantes tres días cada mes, persiguiendo la salud mediante vómitos y lavativas, pensando que a partir de los alimentos que nutren se les producen a los hombres todas las enfermedades".

Lo importante del pasaje hipocrático examinado es la utilización del vómito con fines terapéuticos: conseguir que el paciente pierda la plenitud, y, con ello, que adelgace. El texto hipocrático nos hace pensar en ciertos rasgos de la bulimia actual, seguida de vómitos compulsivos.

Del tratado que nos ocupa puede resultar de interés esta secuencia: "Que usen eméticos: los ( $s c$. seres humanos) bastante húmedos, tres veces al mes; los bastante secos, dos veces, después de comidas de todo tipo; después de los eméticos, que incrementen con calma hasta la alimentación acostumbrada en tres días, con ejercicios bastante ligeros y menos numerosos durante este tiempo", Vict. 3. 68. 6. 596.10-12. 
Un pasaje importante para el estudio de los ejercicios físicos

antes $^{18}$. Y que esté sin desayunar ${ }^{19}$, si es verano; si no es verano, que coma un poco. De la cena ${ }^{20}$ que suprima la mitad de lo que tiene por costumbre

18 Los Tratados hipocráticos son los primeros en registrar el término $\pi \varepsilon \rho i ́ \pi$ tos (perípatos, 78 apariciones en el $\mathrm{CH}$; de ellas 46 en Vict.) dentro de la literatura griega; posteriormente, lo ofrecen, entre otros, Aristófanes, Platón y Jenofonte. El significado, dentro de los tratados médicos hipocráticos, es "paseo"; pero, además, tiene el valor de "lugar para pasear". (Recordemos que los discípulos de Aristóteles fueron llamados "peripatéticos", desde fines del siglo IV a. C., porque iban y venían (caminando en un sentido y en el contrario), durante las lecciones y explicaciones, en el llamado perípatos, especie de claustro cubierto apropiado para pasear.

Queda claro de una secuencia como ésta que el "paseo" no tiene la consideración de "ejercicio gimnástico" a ojos del médico hipocrático (cf. lo dicho en nota 9). Dentro de la indefinición de la cantidad figuran términos como "menos", "más", "poco más", etc. Por lo general, no encontramos precisiones numéricas, indicadoras de exactitud, en casos como éstos.

Debemos fijarnos en el dativo de plural kovфotépolouv, kouphotéroisi, "más ligeros", pues tiene su relevancia cuando se trata de ejercicios físicos. Lo contrario de kouphós (aquí con el sufijo -téros, indicador de comparativo: "más... que"), "ligero, de poco peso", es barýs, "pesado, grave", que aparecerá, también, aplicado a los ejercicios.

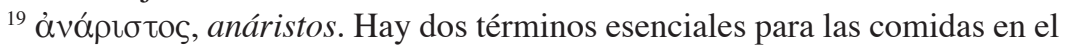

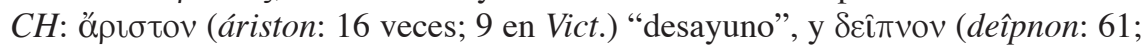
25 en Vict.) "cena”. Ambos sustantivos los encontramos ya en Homero.

Entre las innovaciones léxicas hipocráticas está ỏvóplotoc (anáristos: 8; 6

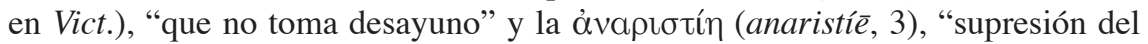
desayuno"(2; sólo en Vict.).

El autor del tratado que revisamos indica que hacer una sola comida

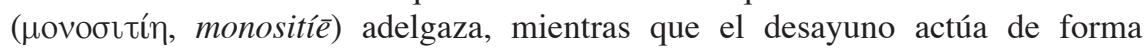
contraria al adelgazamiento, Vict. 3. 60. 6. 574.6.

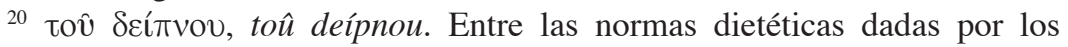
hipocráticos ocupan un lugar relevante las indicaciones sobre los ejercicios físicos que deben preceder o seguir a la cena. Veamos un caso concreto: "Hará una marcha no menor de treinta estadios antes de la cena, y de diez, después de la misma", Int.12. 7. 196. Si el texto transmitido es bueno, en ese mismo tratado (Int. 13. 7. 198) se habla de caminar ciento cincuenta estadios a lo largo del día: noventa, antes de la cena, y veinte, después de ella; además, cuarenta, de madrugada; es decir, un total de casi 29 kilómetros, si se trata del estadio de 192,27 metros. Cf. nota 50 , hacia el final. 
cenar. Al tercer día, reanude todos los ejercicios habituales y los paseos ${ }^{21} \mathrm{y}$, con respecto a los alimentos, increméntelos con calma, para que la alimentación acostumbrada vuelva al quinto día después del vómito. Si tras eso, se encuentra bastante bien, que sea cuidado en lo sucesivo con menos alimentos y más ejercicios. Y si los signos de la plenitud no se detienen, tras dejar pasar dos días desde el que recuperó los alimentos, que vomite de nuevo, y que los incremente según las mismas indicaciones. E, incluso, después de un tercero ( $s c$. vómito), hasta que se libere de la plenitud.

71. Hay algunas personas que, cuando los ejercicios son dominados por los alimentos, experimentan lo siguiente. Comenzando la plenitud, les sobrevienen sueños largos y agradables, e incluso se acuestan un poco durante el día. El sueño se produce al estar la carne humedecida, la sangre fluye y el soplo, dispersándose, se serena ${ }^{22}$. Pero cuando el cuerpo no so-

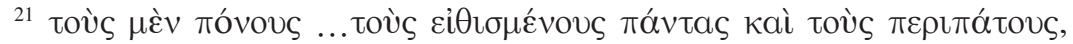
toùs mèn pónous [...] toùs eithisménous pántas kaì toùs peripátous. De nuevo se subraya que el ejercicio, pónos, en general, no es igual que el paseo, perípatos. En un pasaje como el presente puede afirmarse que pónos, "ejercicio", término muy general y de amplio contenido, está muy cerca, o dentro, del ejercicio gimnástico, que acaba de mencionarse unas líneas antes.

${ }^{22} \mathrm{Si}$ poco antes el médico afirma que al comenzar la plenitud ( $\pi \lambda \eta \sigma \mu o v \eta ́$, plēsmonē) les sobrevienen a las personas sueños largos y agradables, queda claro que tal estado favorece el sueño. El hipocrático, entonces, reflexiona en la causa del sueño: la carne llena de humedad. En capítulos posteriores comprobaremos que el objetivo del médico es, mediante ejercicios, sacar esa humedad del cuerpo de su paciente.

Si bien no está estrictamente relacionada con los ejercicios físicos, conviene decir algo sobre la sangre (aîua, haîma). Hemos de aludir aquí a la teoría médica

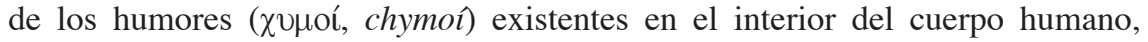
según los hipocráticos. Aunque rara vez se dan juntos, puede hablarse de cuatro humores: bilis amarilla, bilis negra, flema y sangre, en íntima correspondencia con las cuatro propiedades (húmedo/seco, frío/caliente), por lo que, según el humor que predomine en ellos, permite hablar de individuos biliosos, melancólicos, flemáticos y sanguíneos. De la sangre se dice, en el pasaje que estamos viendo, que "fluye"( $\chi$ Eîtal, cheîtai). En otros lugares se afirma que "corre" (@̨̊î, rê̂),

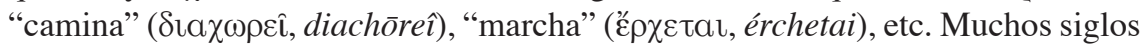
habrán de pasar para que se descubra la circulación pulmonar de la sangre, pero en

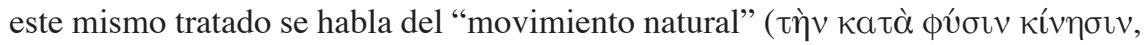
tēn katà phýsin kínēsin) de la misma (Vict. 2. 66. 6. 584.13). 
porta ya la plenitud, provoca dentro, por causa de la violencia del circuito ${ }^{23}$, una secreción, la cual, oponiéndose a la nutrición que viene de los alimentos, perturba el alma. En ese momento, ya no son agradables los sueños, sino que es fuerza que la persona se perturbe y piense que lucha. Pues cuales sean las sensaciones que experimente el cuerpo, tales son las que ve el alma, aunque falte la vista. Por tanto, cuando la persona llega a ese punto, ya está cerca de enfermar. Pero qué enfermedad llegará, es incierto. Pues según sea la secreción que sobreviene y dónde domina, eso produce la afección. Y es preciso que el sensato no deje que avance, sino que, cuando reconozca los primeros indicios, sea atendido con los tratamientos como el anterior, pero necesita más tiempo y el ayuno que mata de hambre ${ }^{24}$.

72. También las siguientes son señales de plenitud. El cuerpo tiene dolor, en unos todo él, en otros una parte del cuerpo, cualquiera que sea. El

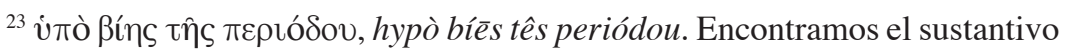
períodos, "camino circular", "circuito". Aparece varias veces en Vict. (cap. 35 (2),

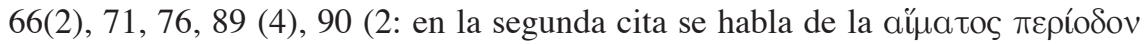
(haímatos períodon), "circuito de la sangre", naturalmente con un sentido muy diferente del que hoy tiene), 93). Algunos especialistas piensan que se comparan los circuitos de las esferas cósmicas con la circulación que tiene lugar dentro del cuerpo humano.

${ }^{24} \lambda$ uнoктovín, limoktoníe. Sólo dos veces tenemos ese término en el $\mathrm{CH}$, donde es una innovación. Vocablo muy raro en la literatura griega; después, sólo lo recogen Platón (1) (Prt. 354 a: presenta como buenos y molestos, al mismo tiempo, los "ejercicios gimnásticos, las expediciones militares y los tratamientos ordenados por los médicos mediante cauterios, cortes, fármacos y dietas de hambre"), Galeno (4) y Alejandro de Afrodisias (1). La mejor definición quizá nos la ofrece Galeno (15.829.9): es una dieta, durante muchos días, consistente en infusión de cebada e hidromiel. 
dolor es como la fatiga ${ }^{25}$. Pensando que tienen agujetas ${ }^{26}$, se hacen tratar con descansos y plenitudes, hasta que llegan a la fiebre. Y de ningún modo reconocen eso tampoco, sino que, tomando baños y alimentos, transforman su enfermedad en pneumonía, y llegan hasta un peligro extremo. Pero es preciso ser previsores, antes que llegue a las enfermedades, y ser tratados de este modo. Sobre todo, tomar baños de vapor suave, y, si no, darse un baño con agua abundante y caliente, relajando el cuerpo lo más posible, y,

${ }^{25}$ ко́тоৎ (kópos) es un sustantivo polisémico en el $\mathrm{CH}$ (38; de ellos, 9 en Vict.): "fatiga, trabajo, sufrimiento". Con el valor de "dolor causado por la fatiga" equivale al español "agujetas". El término surge en el siglo V: lo registran, entre otros, Esquilo, Eurípides, Aristófanes, etc.

Recojo dos ejemplos del tratado que examinamos: "En cuanto a las agujetas (kópōn) que se producen en el cuerpo sucede lo que sigue. Las personas que no hacen ejercicios (hoi mèn agýmnastoi) sufren agujetas (kopiôsi) a resultas de cualquier esfuerzo (apò pantòs pónou). Pues ninguna parte de su cuerpo está preparada para ningún esfuerzo. Los cuerpos ejercitados (tà dè gegymnasména tôn somátōn) sufren agujetas (kopiâ) por obra de esfuerzos desacostumbrados, $\mathrm{y}$, a veces, las sufren por los ejercicios acostumbrados (hypò tôn synēthéōn gymnasíon), si los practican en exceso. Tales son los tipos de agujetas (tôn kópon). El efecto de las mismas es el siguiente: los no ejercitados (hoi mèn oûn agýmnastoi), por tener la carne húmeda, cuando hacen esfuerzos, experimentan un gran derretimiento (sýntêxin pollēn) al calentarse el cuerpo". Vict. 2. 66.6. 582. 12-19; "En los ejercitados (tô̂si dè gymnazoménoisin) las agujetas (ho kópos; en nominativo singular) son producidas por los esfuerzos desacostumbrados a causa de lo siguiente. Cualquier parte en que el cuerpo no esté trabajado, es forzoso que tenga la carne húmeda en ese lugar en que no está acostumbrado a pasar fatigas, como les ocurre en todas partes a los que no hacen gimnasia (agymnástōn) [...] Conviene hacer el tratamiento de este modo: hacer los ejercicios acostumbrados (tô̂si mèn gymnasíoisi [...] toîsi synēthesin), para que el humor concentrado, al calentarse, disminuya y se purgue, y el resto del cuerpo no se humedezca ni se quede sin ejercicio (agýmnaston: en nominativo de singular, neutro)". Vict. II 66.VI 586.1-5. (Subrayo los cuatro términos relacionados con la misma familia semántica. La repetición léxica es un modo de insistir en los conceptos esenciales, recalcando la idea central de un pasaje determinado).

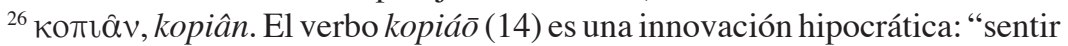
dolor", "tener agujetas". Lo utilizan después Aristófanes, Epicuro, Aristóteles, etc. Ya hemos visto dos secuencias en la nota anterior. Por su interés recojo otra secuencia: "Cuantos tienen agujetas a causa de carreras, menester es que ésos practiquen la lucha. Y cuantos tienen agujetas al practicar la lucha, menester es que ésos corran", Salubr. 7. 6. 82.9.10. 
Un pasaje importante para el estudio de los ejercicios físicos

sirviéndose, en primer lugar, de alimentos ácidos y muy abundantes, y, luego, de los demás, vomitar bien, y, tras levantarse, pasear un poco al sol, $\mathrm{y}$, después, dormir. Al alba, dar muchos paseos, incrementándolos poco a poco $^{27}$, y hacer ejercicios gimnásticos ligeros y con los incrementos ${ }^{28}$ como anteriormente. Ése precisa de un adelgazamiento muy grande ${ }^{29}$ y paseos. $\mathrm{Si}$, por no haberlo previsto, llega a la fiebre, que no le den ninguna otra cosa sino agua durante tres días, si es que cesa en ésos; y, si no, que se le trate con infusión de cebada. Al cuarto o séptimo día saldrá de eso y sudará. Es bueno usar ungüentos sudoríficos ${ }^{30}$ durante las crisis, porque lo ( $s c$. al sudor) obligan.

73. Algunas personas sufren lo siguiente por causa de la plenitud. Les duele la cabeza y la notan pesada, los párpados se les caen después de la cena, tienen perturbación en los sueños, les parece tener fiebre, y, a veces,

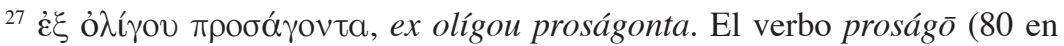
$\mathrm{CH} ; 51$ en Vict. Nótese la importancia del tratado que revisamos por el número de ejemplos ofrecidos) tiene aquí un valor muy concreto, especial, técnico: "incrementar". El sujeto es la persona que está realizando los ejercicios.

Un indicador muy relevante es la frase preposicional ex olígou, "poco a poco". De los 14 ejemplos registrados en el $\mathrm{CH}, 8$ los tiene Vict.

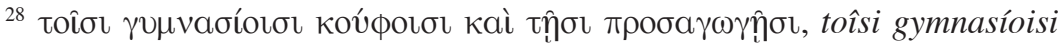
koúphoisi kaì têisi prosagōgêisi. Debemos fijarnos en prosagōgēe, "incremento" (24 en $\mathrm{CH}$; 10 en Vict.), otro término técnico de los médicos, que figuran entre los primeros en usarlo: Heródoto y Tucídides (un ejemplo en cada uno) comparten ese mérito. Para kouphós acúdase a nota 18.

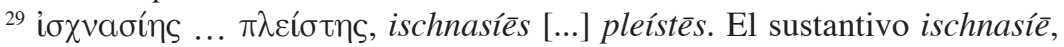
"adelgazamiento" (6 en $\mathrm{CH}$; 5 en Vict.) es otro vocablo correspondiente a la lengua especial de la medicina hipocrática, donde tenemos sus primeras apariciones en la literatura griega. En el siglo IV a.C. tan sólo Aristóteles (4) conoce su uso; posteriormente, lo encontramos en Erotiano (1) y Alejandro de Afrodisias (2); no, en Galeno.

${ }^{30}$ Diversos especialistas han puesto de relieve la capacidad observadora de los médicos hipocráticos a la hora de tomar nota de todo lo que sucede por el exterior del cuerpo: mucosidades, sudor, orina, etc. Comprobaremos más abajo la importancia del sudor para perder plenitud, es decir, peso. En ese sentido es relevante el uso de ungüentos especiales para provocar el sudor, los llamados

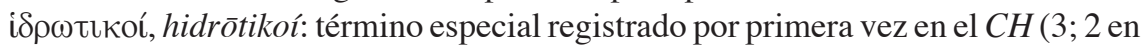
Vict.); lo emplearán en el IV, Aristóteles (1) y Teofrasto (2); después, Dioscórides (2) y Galeno (5). 
el vientre se detiene. Cuando realiza el acto venéreo ${ }^{31}$, parece estar más ligero por el momento, pero, después, está más pesado. En esas personas, la cabeza, atrayendo la plenitud por revulsión ${ }^{32}$, detiene el vientre y se pone pesada. Peligros malos amenazan, y, por donde irrumpe la plenitud, ese lugar se corrompe. Es preciso precaverse del siguiente modo. Si se quiere aplicar un tratamiento bastante rápido, tras darse un baño de vapor, que sea purgado con heléboro, $\mathrm{y}$, después, incrementar con alimentos ligeros y blandos durante diez días. Y con comidas laxantes, para que la cavidad ${ }^{33}$ inferior domine a la cabeza con una revulsión por abajo. Y carreras lentas ${ }^{34}$,

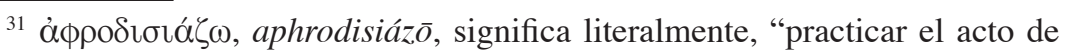
Afrodita", la diosa de la unión sexual; lo tenemos por primera vez en el $\mathrm{CH}$ (7). Valiéndonos del equivalente latino de la diosa, en español se habla de realizar el acto venéreo, es decir, el relacionado con Venus, la Afrodita romana.

Dentro de las normas dietéticas, de régimen de vida, el hipocrático se ocupa de las relaciones sexuales. En los capítulos que estamos revisando lo encontraremos otras dos veces. Los médicos observan qué sucede antes, o después, de llevar a cabo la unión sexual. Efectivamente, el médico, más adelante, recomienda lo

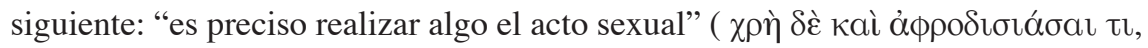
chrē dè kaì aphrodisiásai ti ), Vict. 3. 80. 6. 628.1, donde tenemos un acusativo de contenido ( $t i)$, "algo, un poco", que, en este caso, precisa y limita la idea verbal. Otra indicación nos la da el mismo autor cuando presenta ciertas normas para un caso en que los ejercicios prevalecen sobre los alimentos: "Y realice el acto sexual

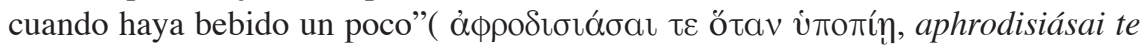
hótan hypopiéi), Vict. 3. 85.6. 636.13.

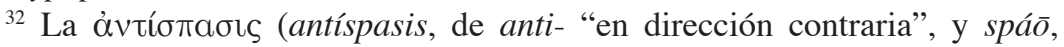
"atraer, arrastrar, tirar"), es decir, "acción de arrastrar en sentido contrario", "revulsión”, es una aplicación concreta de un principio médico muy conocido, la curación por los remedios contrarios (contraria contrariis curantur). Se trata de provocar una pérdida de sangre, un gran esfuerzo y ejercicio intenso en alguna parte del cuerpo. Para el hipocrático, nada le resulta más conveniente que atacar la parte opuesta al lugar del cuerpo en que se halla la enfermedad o el dolor, aplicando ventosas, cauterios, medicamentos irritantes, emplastos u otro tipo de remedios. La revulsión aparece por primera vez en los tratados hipocráticos, donde la tenemos en 7 ocasiones. Es un procedimiento natural con finalidad terapéutica.

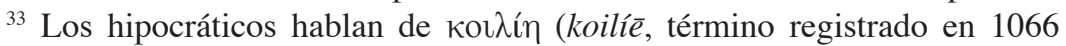
ocasiones), "cavidad" de un modo no siempre claro; en general, cabe distinguir una cavidad superior (la torácica) y otra inferior (la abdominal). Tal sustantivo es más frecuente en plural.

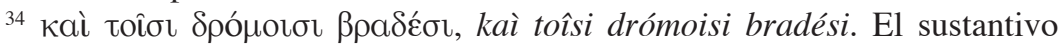
drómos (piénsese en términos del español como hipódromo, aeródromo) es el 
Un pasaje importante para el estudio de los ejercicios físicos

paseos al amanecer, suficientes ${ }^{35}$, y lucha con aceite ${ }^{36}$; y que tome el término común en el $\mathrm{CH}$ para referirse a la "carrera"; está registrado 33 veces; de ellas, 19 en Vict. Con frecuencia se nos dan indicaciones: en nuestro ejemplo, "lentas" ( $\beta \rho a \delta ́ \varepsilon \_l$, bradési). Otras precisiones en contextos diferentes: "rápidas"

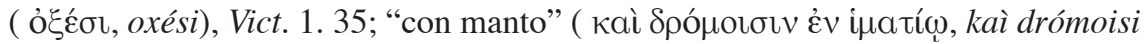
en himatíoi), Vict. 2. 63 y 4. 89 (bis).

El adjetivo bradýs, "lento", se opone a oxýs y tachýs, "rápido". No suele haber apreciaciones explícitas sobre en qué consistía la lentitud o la rapidez. De entre más de 49 usos en el $\mathrm{CH}$, sólo 10 recogen el adjetivo en grado positivo (como en el ejemplo que examinamos); los demás están en comparativo (bradýteron) sin segundo término de la comparación, con un valor intensivo: "bastante lento".

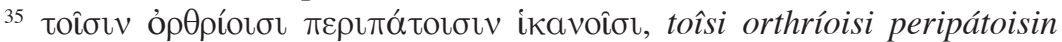
hikanoîsi. El término perípatos, ya visto en nota 18, recibe, en este texto, dos adjetivos muy significativos: órthrios y hikanós. El primero (cf. nota 8) es tan relevante que en 6 ocasiones acompaña a perípatos. En efecto, órthrios es propiamente lo que sucede al alba, antes que salga el sol, es decir, en los primeros momentos de la mañana, cuando apenas se vislumbran las luces del nuevo día.

Por su lado, la cantidad se expresa, frecuentemente, con adjetivos cuantificadores, de carácter impreciso en no pocas ocasiones: "mucho, poco, bastante, escaso, suficiente". Así, hikanós, "suficiente", cuando se trata de cosas; lo tenemos 60 veces en el $\mathrm{CH}$. Naturalmente, era el médico el encargado de dar el calificativo de "suficiente" cuando se trataba de ejercicios físicos o paseos, como en este caso.

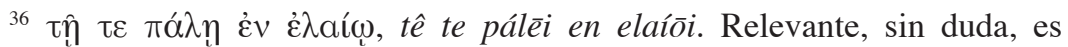
pálē, "lucha", presente 22 veces en el $\mathrm{CH}$; precisamente en Vict. encontramos 15 ejemplos. Está registrada desde Homero (Es un sustantivo distinto de $\pi v \gamma \mu \eta ́$ (pygmē), "lucha con los puños" o "pugilato", vocablo también homérico (1), que, posteriormente utilizan, entre otros, Píndaro, Sófocles, Eurípides, Aristófanes, Platón, etc.; lo registra, asimismo, el $\mathrm{CH}$, pero con el valor de "puño").

En los escritos hipocráticos tenemos varias indicaciones sobre cuándo, dónde y cómo se practica la lucha: por la mañana; en el polvo; poca (Vict. 3. 78); corta (Vict. 3. 79); blanda (Vict.3. 75), con aceite (Vict. 3. 68 (tres veces), 73, 75 (en estos dos capítulos insistiremos; en 73, concretamente, sobre lo referente a la expresión preposicional "con aceite"), 79; otras veces, se recomienda que no se realice: Vict.3. 81, por ejemplo, como veremos más abajo.

Creo importante ofrecer el siguiente pasaje en donde se está hablando de Heródico de Selimbria (Selimbria era una colonia de Mégara, cercana a Bizancio, o sea, la actual Estambul). Diversas fuentes nos hablan de él como un hombre de gran entereza y enorme fuerza de voluntad, pues, estando aquejado de grave enfermedad, se aplicó a sí mismo un régimen de vida tan estricto (ejercicios y masajes, esencialmente) que consiguió recuperar la salud. En general, los cono- 
desayuno y eche un sueño no largo tras el desayuno. Después de la cena, cimientos que había adquirido en la palestra le sirvieron para la constitución de su famoso método curativo: "Heródico mataba a los que padecían fiebres con carreras (drómoisi), muchas luchas (pálēisi pollêisi), baños de vapor: malo. La fiebre es enemiga de las luchas (polémion pálēisi), de los paseos, de las carreras (periódoisi, drómoisin), de las fricciones; fatiga con fatiga (pónos pónōi) en ellos: hinchazón de las venas, enrojecimiento, lividez, palidez, dolor de los costados sin hinchazón", Epid. 6.3.18. 5. 302.2.

Aparte de los ejemplos que examinaremos en el texto estudiado, doy otros tres del mismo tratado. Una recomendación para el individuo en quien coinciden la parte más húmeda del fuego y la más seca del agua (recordemos que el autor de Sobre la dieta cree que todos los seres, y el hombre entre ellos, están compuestos, esencialmente, de agua y fuego): "A ése le conviene usar más bien una dieta (diaítê) inclinada hacia el agua, guardándose de excesos en comidas, bebidas y ejercicios (pónōn), y sin cometer exceso alguno en carreras de fondo, las de doble estadio, lucha y todos los demás ejercicios gimnásticos (drómoisi kamptoîsi kaì diaúloisi kaì pálēi kaì toîsin álloisi gymnasíoisi pâsin), Vict. 1. 35. 6. 518.17; "La lucha y la fricción (pálē dè kaì trípsis) procuran más ejercicio (pónon) a las partes exteriores del cuerpo, calientan la carne, la endurecen y la desarrollan por los motivos siguientes [...]", Vict. 2. 64. 6. 580.9; "La lucha en el polvo (alíndēsis) tiene efectos parecidos a la lucha (pálēi), pero reseca más a causa del polvo y desarrolla más las carnes. La lucha con las puntas de la mano (akrocheírixis) reseca (ischnaínei, lo que puede significar también "adelgaza") y arrastra hacia arriba las carnes; y el combate contra el saco (kōrykomachíe ) y el movimiento rítmico de los brazos (cheironomié) tienen efectos parecidos", Vict. 2. 64. 6. 580.15.

Introduzco un excurso sobre un término muy importante relacionado con pále, a saber, palaístre (o palaístra), es decir, el lugar donde se practica la lucha entre atletas. Es un sustantivo que aparece en el siglo V a. C.: Heródoto, $\mathrm{CH}$ (4), Eurípides, Aristófanes, etc. Recojo tres ejemplos del $\mathrm{CH}$ : " Cuando se quiere tomar un baño, si se ha ejercitado en la palestra, que sea frío". Vict.3. 68. 6. 596.7; en otro lugar, el hipocrático está hablando de la curvatura del raquis o desviación de la columna y de cómo ha de actuar el médico: recomienda baños de vapor con mucha agua caliente; que el enfermo se acueste boca abajo, que se le aten las piernas, brazos y cintura, y así se le pueda practicar la reducción de la gibosidad : "Nada impide que se practique una sucusión suave, mientras se hace una ligera presión apoyando el pie sobre la gibosidad. Alguno de los que están acostumbrados a la palestra es apropiado para hacer estas maniobras", Art. 47. 4. 206.15; dentro de este mismo tratado, titulado en español Sobre las articulaciones, a la hora de poner en su sitio un hombro dislocado, es decir, reducir una luxación, se nos dice lo siguiente: "Todas esas reducciones son bien útiles en la palestra, ya que no se requiere poner al paciente sobre ningún aparato y cualquiera puede usarlas en cualquier sitio", Art. 4. 4. 86.10. 
Un pasaje importante para el estudio de los ejercicios físicos

sólo con levantarse ${ }^{37}$ es suficiente. Y bañarse, y friccionarse; bañarse con agua tibia, y abstenerse del coito ${ }^{38}$. Ese es el tratamiento bastante rápido.

Si no quisiera tomar fármacos, tras darse un baño con agua caliente, que vomite después de tomar alimentos ácidos, húmedos, dulces y salados, y, después del vómito, sólo que se levante; al alba, aumente progresivamente los paseos tranquilos y los ejercicios gimnásticos descritos ${ }^{39}$, durante seis

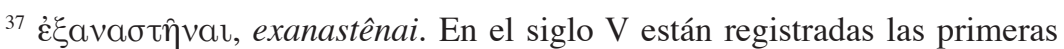
apariciones de exanístēmi, verbo polisémico. El $\mathrm{CH}$ lo presenta en 20 ejemplos: "levantarse" de la cama, del lugar donde alguien está sentado, etc. Vict. ofrece 4 veces la fórmula hóson exanastênai, "sólo levantarse".

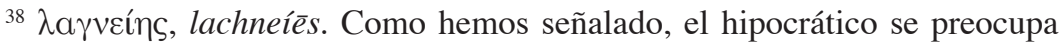
por la actividad sexual de sus pacientes como uno de los elementos propios de la dieta, entendida como régimen de vida. Lagneíe (22), "relación sexual", "coito" corresponde a una familia de palabras que indican "debilidad, blandura"; así, pues, una apropiada traducción de nuestro vocablo sería "molicie". En una innovación del $\mathrm{CH}$, así como lágneuma (4), que apunta al resultado de tal actividad, y, asimismo, el verbo lagneúō (15).

Daré algunos ejemplos para el lector interesado. En el tratado que estamos examinando se nos dice que "la relación sexual adelgaza, humedece y calienta. Calienta por el esfuerzo y la excreción de lo húmedo; adelgaza, por la vacuidad; humedece por lo que queda en el cuerpo de la parte fundida por causa del esfuerzo", Vict. 2. 58. 6. 572.1; "Utilizar la unión sexual mucho en esta estación (sc. el invierno): los de bastante edad, más que los jóvenes", Vict. 3. 68. 6. 596.9.

Si pasamos al verbo, el hipocrático, buen observador, nos habla de una joven sirviente que sentía intenso dolor cuando tenía relaciones sexuales (Epid.5. 25.5. 224.7); asimismo, leemos que cuando los hombres tienen una relación sexual, a pesar de haber eyaculado poca cantidad, se sienten débiles (Genit.1.7. 470.7); y, además, que, en el hombre que realiza mucho el acto sexual, las venas, al hacerse bastante anchas, provocan tal acto (Nat. puer.21.7. 514.4); por su lado, se nos dice que los escitas son malísimos para llevarlo a cabo (Aër. 22. 2. 80.18); etc.

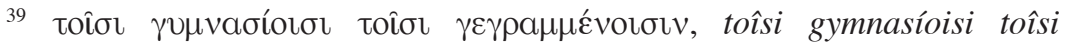
gegramménoisin. Indicio inequívoco de que la actividad física se estaba convirtiendo en una verdadera arte es el detalle de recoger por escrito (gegramménoisi, propiamente, "que están escritos", "que han quedado escritos") las indicaciones en materia de ejercicios gimnásticos, con lo que la gymnastike (arte de los ejercicios gimnásticos) empieza a ocupar un lugar paralelo y equivalente a la iatrikē (arte de la medicina).

Precisamente, la gymnastikē aparece dos veces en el $\mathrm{CH}$ : "La gimnástica y la medicina (gymnastikè dè kaì iêtrikē) son por naturaleza contrarias, pues la gimnástica (hē mèn gàr gymnastikē) no necesita procurar cambios, pero la 
días. Al séptimo, tras producirse una plenitud a partir de alimentos semejantes, provocar un vómito e incrementar de la misma manera. Practicar esas normas durante cuatro semanas, pues, precisamente en ese tiempo, se restablece. Después, incrementar progresivamente con alimentos y ejercicios, y producir vómitos en mayor intervalo de tiempo e incrementar los alimentos en menos tiempo, para que el cuerpo se recupere, y restablecer poco a poco la dieta a lo habitual.

74. Se producen también los siguientes hechos a partir de la plenitud. En cuantos el vientre digiere el alimento, pero las carnes no lo admiten, la nutrición, al detenerse, produce flatulencia. Pero cuando desayuna, se restablece, pues lo especialmente ligero es expulsado por lo especialmente fuerte, y piensan que se han liberado, pero eso, mucho mayor, se presenta al día siguiente. Y, cuando aumentando cada día se vuelve fuerte, lo que queda domina a los alimentos que se han introducido y recalienta y perturba todo el cuerpo y produce diarrea. Se llama así, mientras sólo el alimento corrompido sea evacuado por abajo. Cuando, al calentarse el cuerpo, la

medicina, sí. Pues al sano no le conviene cambiar de su situación presente, pero al enfermo, sî́, Loc.Hom.35.6. 326.22-23. Nótese que la sustantivación del adjetivo gymnastikós (aquí en femenino) se lleva a cabo en este pasaje de dos formas: la primera, por ser sujeto del verbo, con lo cual funciona como un sustantivo; la segunda, mediante el artículo. Varios instrumentos bibliográficos citan, como primer ejemplo de he gymnastike, las obras de Platón, que la emplea en 86 ocasiones. Sin embargo, es muy probable que el texto hipocrático sea anterior en el tiempo. En ese ejemplo hipocrático tenemos el femenino, que alude a un arte que sabe dar razones de lo que hace. Es el momento en que surgen docenas y docenas de términos especiales dotados del sufijo $-i k \bar{e}$, propio para indicar, en este caso, la pertenencia a un arte especial. El campeón indiscutible en crear tales neologismos es, sin duda, Platón.

También, creo, es una innovación del $\mathrm{CH}$ el uso del masculino (gymnastikós) ( 1 en $\mathrm{CH} ; 7$ en Platón): "En los gimnastas (en toîsi gymnastikoîsin), las buenas disposiciones (euexíai) llevadas al extremo son peligrosas, si están en el último grado", Aph. 1. 3. 4. 458.13. Los estudiosos están de acuerdo en que gymnastikós funciona aquí como sustantivo, pues se habla, no "de lo correspondiente al ejercicio gimnástico", sino "del especializado en ejercicios gimnásticos". Es un texto de singular relevancia que mereció un comentario extenso de la pluma de Galeno (In Hipp. Aph. 1. 3.17 B 362-367, o sea cinco páginas de la edición preparada por Kühn), en donde los atletas son considerados un ejemplo extraño de buena forma física, pues se encuentran en una situación en que sería peligroso cualquier cambio. 
Un pasaje importante para el estudio de los ejercicios físicos

purga resulta agria, el intestino es rascado y ulcerado y se hacen deposiciones sanguinolentas. Eso se llama disentería, enfermedad grave y peligrosa. Pero es preciso prever y suprimir el desayuno y una tercera parte de la cena. Practicar más ejercicios, luchas, carreras y paseos, tanto después de los ejercicios gimnásticos como de madrugada ${ }^{40}$. Cuando se cumplan diez días, añadir la mitad del alimento suprimido, y provocar un vómito e incrementar hasta los cuatro días. Y cuando pase otra decena ( $s c$. de días), añádase la comida restante y provóquese un vómito, e, incrementando en lo referente a la comida, lo pondrás sano en ese tiempo. Ten confianza cuando oprimas ${ }^{41}$ a tal persona con ejercicios.

75. Se producen también los siguientes. Al día siguiente se vomita el alimento crudo sin ardor de estómago, y el vientre evacua, menos de lo que corresponde a los alimentos, pero, con todo, de modo suficiente, y ninguna fatiga se presenta. En ésos, el vientre, siendo frío, no puede digerir el alimento por la noche. Por tanto, cuando se pone en movimiento, vomita la comida cruda. Por consiguiente, a ése se le debe procurar calor en el vientre a partir de la dieta y los ejercicios. En primer lugar, por lo tanto, hay que

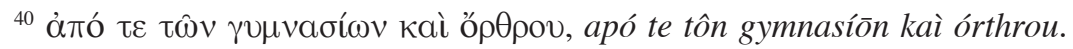
Estamos ante un importante uso preposicional de gymnásion, "ejercicio físico", o "gimnástico". Se trata de indicar que algo tiene lugar "después de los ejercicios físicos”. El griego lo expresa, especialmente, con apó más genitivo. El médico hipocrático, extraordinario testigo del mundo que le rodea, anota cuidadosamente todos los casos en que advierte cualquier peculiaridad o anomalía con posterioridad a la realización de alguna actividad física. Veamos algunos textos de interés aparte de los que encontraremos, más adelante, en los capítulos 75, 81 y 82: “A ése le conviene dar muchas carreras con ropa puesta, aumentándolas poco a poco, para sudar lo más posible; y muchos paseos tras el ejercicio gimnástico”, Vict. 4. 89.6. 646.5; "Los paseos después de los ejercicios gimnásticos dejan purgados los cuerpos y los adelgazan", Vict.2. 62. 6. 578.7; "Dar paseos rápidos tras los ejercicios gimnásticos, lentos y al sol tras la comida, y muchos paseos de madrugada, comenzando poco a poco, avanzando a ritmo vivo y acabando con calma",Vict. 3. 68. 6. 596. 2; "Y hay que dar paseos más numerosos tras los ejercicios físicos", Vict. 4. 90. 6. 654. 14.

${ }^{41} \pi \imath \dot{\varepsilon} \zeta \omega v$, piézōn, propiamente, "apretando". De notable interés es esta admonición que el médico redactor de la obra dirige a otro profesional de la medicina a fin de que la lea o lleve a la práctica lo que en ella se incluye. El verbo $\pi \iota \hat{\varepsilon} \zeta \omega($ piézō) significa “apretar, oprimir, constreñir”, quizá con el propósito de "hacer adelgazar". 
emplear pan caliente fermentado, haciéndolo pedazos en vino tinto o en hervido de cerdo. Y pescados hervidos en salmuera picante; y emplear carnes, como pies de cerdo cocidos y cerdos grasos asados, pero no muchos cochinillos ni (sc. carnes) de perritos ni de cabritos. Y hortalizas: puerros y ajos cocidos o crudos, acelgas cocidas y calabazas. Bebidas bastante puras, sueños largos, y sin desayuno el primer día. Y sueños después de los ejercicios gimnásticos; y las carreras de fondo, incrementándolas poco a poco, y la lucha suave, con aceite ${ }^{42}$, y pocos baños, más unciones, muchísimos

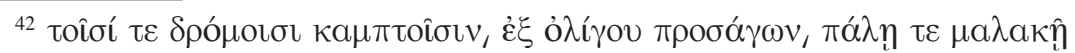

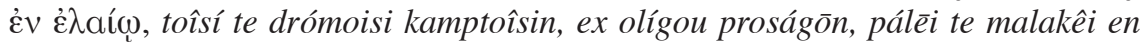
elaíoi Ya nos hemos detenido en el término drómos: cf. nota 34. Aquí se trata de una carrera especial que hemos traducido como "de fondo". El griego nos dice kamptoîsi, dativo de plural de kamptós. El CH presenta en 8 ocasiones ese adjetivo, y, entre sus usos, destacan los 6 ejemplos en que se habla de drómoi kamptoí, todos ellos en Vict. Efectivamente, kamptós, "flexible, que gira, que dobla" es un término técnico para denominar la carrera que se hacía en el estadio, o en otras

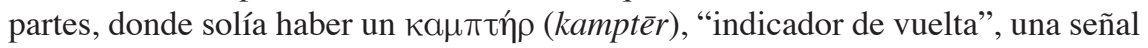
en donde los corredores doblaban cuando estaban practicando el doble estadio (kamptēr, presente ya en Jenofonte, no aparece con el sentido que nos interesa hasta Aristóteles: $R h .3 .8 .1409$ a 32: "por lo cual, junto a los indicadores de vuelta (epì toîs kamptêrsi), (sc. los corredores) pierden el aliento y desfallecen, pues no se cansan antes, mientras están viendo la meta".

Hay varios precedentes de tal tipo de carrera. Ya en Esquilo, A.. 344, por boca de Clitemnestra que está refiriéndose a los aqueos que han de volver desde Troya a la patria, se nos dice así: "pues es preciso la salvación del regreso a sus hogares:/ doblar (kámpsai) de vuelta la otra parte del diaulo".

Un término relevante es proságōn, participio de presente de proságō, "añadir, incrementar", término técnico usado por los médicos; con frecuencia, sin complemento directo, es decir, sin indicación explícita de qué es lo que se incrementa. En cada ocasión es el contexto próximo o remoto el que puede ayudar a dar una respuesta.

Dentro de la pálē (cf. nota 36) se trata de la clase malakē, "suave, blanda"(el adjetivo latino correspondiente es mollis, "muelle, blando"); es la única vez en que se aplica a dicho sustantivo. Por lo demás, malakós lo encontramos 62 veces en $\mathrm{CH} ; 26$ en Vict.

Es relevante, asimismo, la indicación de que sea una lucha, "con aceite", es decir, untándose el cuerpo con tal producto. Las seis veces en que aparece esa precisión en el $\mathrm{CH}$, todas ellas se dan en el tratado Vict. En el libro 3, capítulo 68, el autor comienza diciendo que está escribiendo para la gran mayoría de hombres, tanto en lo referente a comidas y bebidas, como en lo pertinente a ejercicios 
Un pasaje importante para el estudio de los ejercicios físicos

paseos de madrugada y pocos después de la cena. Y los higos, tras los alimentos, son buenos, y vino puro con ellos. Después de este tratamiento llega la recuperación; para unos, con más rapidez; para otros, con más lentitud.

76. Algunos otros sufren lo siguiente. Pierden el color, y, cuando comen, vomitan poco después sustancias ácidas, y la acidez sube a la nariz. Los cuerpos de éstos no están puros ${ }^{43}$, y la parte de carne que se funde por

obligatorios (pónoisí te tô̂si anankaíoisin), caminatas que sean por necesidad (odoiporíeisí te têisi pròs anánkas) e, incluso, viajes por mar para conseguir medios de vida. En tales casos, en el invierno, que practique "los ejercicios, muchos, de todas clases, y las carreras de fondo incrementándolas poco a poco, y la lucha con aceite, larga, obligándose a partir de ligeros comienzos (tô̂si te pónoisi polloîsi hápasi, toîsí te drómoisi kamptoîsi ex olígou proságonta, kaì te pálēi en elaíoi makrêi apò koúphōn prosanankázonta)", Vict. 3. 68. 6. 596.1; en primavera, conviene hacer "lucha con aceite, al sol" (kaì têi pálēi sỳn tôi elaíoi en tôi helíoi chrêsthai), 3. 68. 6. 600.14; y, con respecto al otoño, leemos: "tras moverse previamente envuelto en un manto, dedicarse en esta época al masaje y la lucha con aceite, incrementando con calma" (têi pálēi têi en elaíói hesychêi proságonta), 3. 68. 6. 604.11.

En Vict., a propósito de la lucha, tenemos en seis ocasiones el giro preposicional en elaíoi , en donde la preposición en funciona con valor, no local, sino instrumental (no "en aceite", sino "con aceite"; entiéndase, untado con ese líquido); es un uso normal en poesía; sólo un ejemplo hallamos de otra fórmula: sỳn tôi elaíoi $i$, en donde no cabe dudar del valor instrumental: "con aceite".

Por lo demás, para el lector interesado puede resultar importante leer Vict. 2. 65 para examinar las diferencias entre los ejercicios gimnásticos realizados en el polvo y los que se efectúan con aceite (tà en elaíoi gymnasía): en invierno, el aceite ayuda al desarrollo, al impedir que el frío arrebate nada del cuerpo; en cambio, durante el verano, el aceite produce exceso de calor y hace que se funda la carne. Por el contrario, el polvo favorece el desarrollo durante el verano, pues refresca el cuerpo y no permite que se recaliente en exceso, pero, en invierno, enfría y produce congelación. Así, estar un rato en el polvo durante el verano sirve de provecho, porque refresca; con todo, cuando se está mucho tiempo en él, reseca en exceso y deja los cuerpos secos y duros. Si se frota el cuerpo con aceite mezclado con agua, se consigue reblandecerlo y se impide que se caliente en exceso.

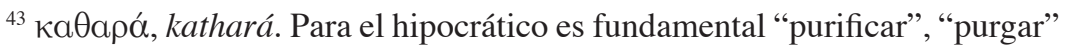
(kathaírō) los cuerpos; la "purga" (kátharsis) se aplica, no sólo a las cavidades (superior, mediante vómitos; inferior, gracias a purgantes), sino a otras partes del 
obra del ejercicio es mayor que la que se purifica por efecto del circuito ${ }^{44}$. Esa parte, quedándose, se opone a la alimentación, la fuerza y la vuelve ácida. Por tanto, el alimento es vomitado y aquella parte se ve rechazada bajo la piel y produce en la persona palidez y genera enfermedades hidrópicas. Mas es preciso prever de la siguiente manera. El tratamiento bastante rápido: que beba heléboro ${ }^{45}$, incrementando poco a poco, como antes he dejado escrito. Pero el más seguro es por obra de la dieta, como sigue. En primer lugar, tras un baño caliente, provocar un vómito; luego, incrementar, hasta en siete días, el alimento habitual. Al décimo día, tras el vómito, que vomite otra vez, e increméntese según la misma medida. Y hágase del mismo modo por tercera vez. Que realice carreras, pocas y rápidas, y movimientos hacia arriba y fricción, con larga estancia en el gimnasio, y practique la lucha en el polvo ${ }^{46}$.Y muchos paseos después de

cuerpo humano (cerebro, pulmón, etc.) a fin de conseguir que todas y cada una de ellas resulten katharaí, "puras, purificadas".

El origen de la kátharsis suele buscarse en la purificación ritual, mediante la cual un individuo, grupo humano o ciudad, limpiaban sus culpas y quedaban puros.

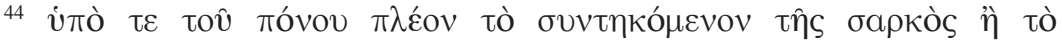

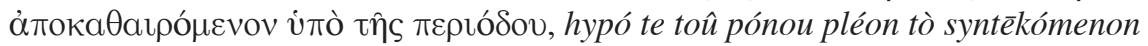
tês sarkòs $\bar{e}$ tò apokathairómenon hypò tês periódou. Una teoría basada en la analogía es la que sostiene que el ejercicio (pónos) funde (tēkō; en el texto que revisamos se nos presenta el participio de presente del verbo compuesto: syntēkómenon, "lo que juntamente se funde") las carnes. Otro aserto puramente analógico consiste en afirmar que el circuito (períodos, cf. nota 23), o circulación interna, purifica esa carne fundida que queda en el interior del cuerpo.

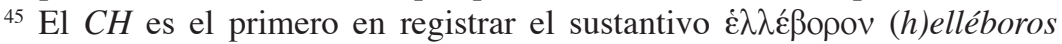
(106) y sus derivados. En los Aforismos hallamos algunas indicaciones sobre tal sustancia, recomendada para vomitar y mover el vientre. Posteriormente, Galeno se ocupó de las dos clases de heléboro: el blanco, usado como emético, y el negro, como purgante.

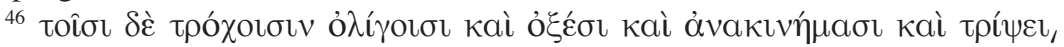

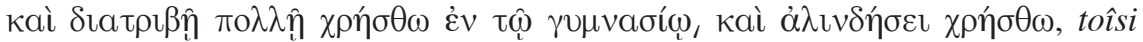
dè tróchoisin olígoisi kaì oxési kaì anakinèmasi kaì trípsei, kaì diatribêi pollêi chrēstho en tôi gymnasíöi, kaì alindēsei chrēsthō. Esta secuencia merece varias anotaciones. En primer lugar, se habla de tróchoisi oxési, "carreras rápidas". En realidad, tróchos, "carrera", es una especie de drómos, término genérico que abarca varias especies dentro de su sentido más general. Todos los ejemplos de tróchos dentro del $\mathrm{CH}, 15$, están en Vict. En el pasaje que ahora revisamos tenemos una subespecie, las carreras oxê̂s (en nominativo de plural; oxýs, 
Un pasaje importante para el estudio de los ejercicios físicos

los ejercicios gimnásticos, y que los dé también después de cenar, y

nominativo de singular); en otras dos ocasiones habla el tratado que revisamos de este tipo de carrera: en los capítulos 81 (como veremos) y 89. Algunos editores de este tratado (Littré, entre ellos) prefieren la lectura trochós (así la presentan, en general, los manuscritos) y traducen el sustantivo por "carrera circular", pero es una interpretación no aceptada hoy día.

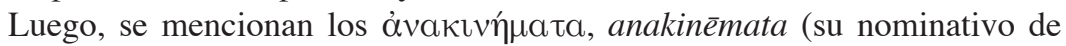
singular es àvakívๆua, anakínēma), innovación hipocrática, donde la tenemos sólo dos veces, en plural. La etimología nos hace pensar en "movimientos hacia lo alto, hacia arriba, o en alto", posiblemente de los brazos. La otra mención es de Vict. 2. 64. 6. 580.7: "Los movimientos en alto y las elevaciones (sc. de brazos) (tà dè anakinèmata kaì anakouphísmata) calientan muy poco la carne, pero estimulan a la vez el cuerpo y el alma y los vacían de aire". Fuera del $\mathrm{CH}$, nos ofrece el término, en dos ocasiones, Hesiquio, lexicógrafo del siglo V d. C. Efectivamente,

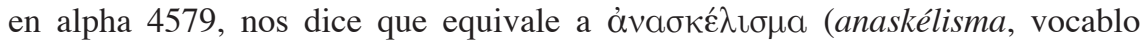
recogido sólo en este autor), "movimiento de los brazos hacia arriba, o en alto".

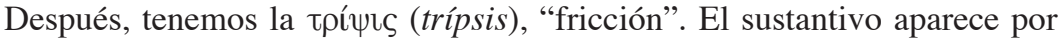
primera vez en el siglo V; Sófocles y Heródoto lo recogen sólo en una secuencia; luego lo encontramos 13 veces dentro del $\mathrm{CH} ; 10$ de ellas, en el tratado que revisamos. En Vict. 2. 65 se señala que la "fricción de aceite con agua ablanda y no permite que ( $s c$. el cuerpo) se caliente mucho". Otros pasajes nos presentan varios tipos de fricción: "abundante", "escasa", "reposada", etc.

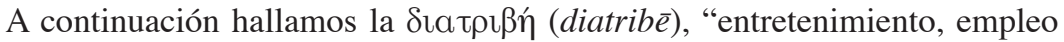
del tiempo, demora", término que surge en el siglo V (Tucídides, Sófocles, Eurípides, Aristófanes). El $\mathrm{CH}$ sólo lo presenta en 4 ocasiones. Será un vocablo muy importante en la filosofía posterior. En el tex to que analizamos se recomienda que ese tiempo sea mucho (pollêi).

Además, el sustantivo youvóouov (gymnásion), con el sentido de "lugar para los ejercicios gimnásticos, gimnasio". Aunque ese vocablo aparece a comienzos del V (quizá a finales del VI, si es auténtico un texto de Anacreonte, Epigramas, 143.4) con el valor de "ejercicio físico", puede decirse que el $\mathrm{CH}$ figura entre los primeros en registrarlo con el sentido de "gimnasio", a pesar de lo que indican ciertos instrumentos léxicos, cuando recogen tal valor a partir de Eurípides, Fenicias 368 (obra del 410 a. C.). Dentro del CH, lo encontramos, con tal acepción, al menos en otro contexto. Hablando de la primera constitución, en sentido médico (conjunto de circunstancias meteorológicas y naturales: vientos, lluvias, lugares, posición de los astros, etc.), referida concretamente a la isla de Tasos, y aludiendo a las hinchazones que les sobrevinieron a los pacientes junto a los oídos, leemos: "Ésas se produjeron en los adolescentes, y en los que estaban en la flor de la edad, $\mathrm{y}$, de entre éstos, en los muy numerosos que acudían a la palestra y a los gimnasios

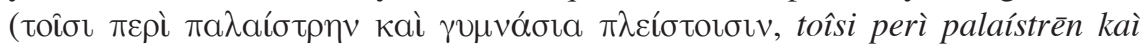


muchísimos de madrugada. Y cubierto de polvo, que se dé unciones. Y, cuando quiera bañarse, que se dé un baño caliente. Y, sin desayunar, que pase ese tiempo. Y si se recupera en un mes, que sea tratado, en lo sucesivo, con los medios convenientes. Y si queda algo, empléese el tratamiento.

77. Hay algunos en que, al día siguiente, se les producen ardores de estómago. A ésos, por la noche, se les produce secreción a partir de la plenitud. Por tanto, cuando el cuerpo se mueve después del sueño, teniendo una respiración bastante frecuente, algo caliente y ácido es expulsado fuera con la respiración; a partir de eso surgen enfermedades, si uno no se vale de precaución. Les interesa también a ésos ser tratados como el caso anterior. Pero que ésos hagan más ejercicios.

78. A algunos les sucede también lo siguiente. En los cuerpos de carne densa, cuando los alimentos se calientan y se disuelven después del primer sueño, calentándose la carne por obra de los alimentos durante el sueño, se produce gran secreción a partir de la carne, que está húmeda. Después, la carne, siendo densa, no admite el alimento, y lo que se segrega de la carne, oponiéndose al alimento y siendo rechazado hacia fuera, sofoca a la persona y la calienta, hasta que vomita. Luego se queda más ligera. Ninguna molestia aparente en el cuerpo, pero hay palidez. Pasando el tiempo, se presentan molestias y enfermedades. Experimentan también cosas parecidas a ésos, cuantos ajenos a los ejercicios gimnásticos ${ }^{47}$, habiéndose esforzado gymnásia pleístoisin)", Epid. 1. 1. 2. 602.3 (Es una precisión que demuestra la extraordinaria capacidad de observación del hipocrático: constata en quiénes se dan determinadas afecciones; los localiza dentro de una edad determinada; dentro de ésta, señala concretamente un grupo particular, según sus actividades deportivas y los lugares donde las practican).

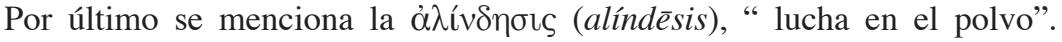
Término técnico, sólo lo registran el CH (5; todos en Vict.) y, nueve siglos después, Oribasio (1). Veamos dos secuencias: " La lucha en el polvo consigue efectos parecidos a la lucha, pero reseca más a causa del polvo y produce menos carne", Vict. 2. 64. 6. 580.14; "La lucha en el polvo es mejor que las carreras (tróchoi), pues éstas resecan el cuerpo vaciándolo de su humedad", Vict. 3. 68. 6. 602.18.

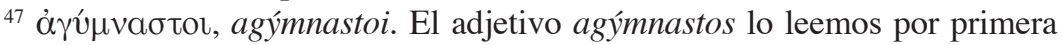
vez en el siglo V (lo tienen Sófocles (1) y Eurípides (4), pero no en el terreno de los ejercicios gimnásticos); asimismo, está presente 7 veces en el $\mathrm{CH}$ (de ellas, 5 en Vict.), ya con sentido técnico, especial: "el que no practica ejercicios gimnásticos" (la primera $a$ (alfa en griego) es la llamada privativa, es decir, la que indica carencia 
Un pasaje importante para el estudio de los ejercicios físicos

de pronto ${ }^{48}$, causan una gran fusión ${ }^{49}$ de carne. Es preciso tratar a ésos del modo siguiente. Suprimir de los alimentos la tercera parte; consumir alimentos ácidos, secos, astringentes, bienolientes y diuréticos; y muchísimas carreras de fondo, con manto, y, desnudo, tanto carreras dobles como carreras $^{50}$; fricciones y poca lucha; y luchas con la punta de las manos; la

o negación de algo). Ya hemos visto dos ejemplos importantes en la nota 25 . He aquí otra secuencia más: "Los cuerpos ejercitados y densos (tà gegymnasména kaì pykná) perecen por obra de afecciones pleuríticas y peripneumónicas con más rapidez que los faltos de ejercicio (tôn agymnástōn)", Coac. 392. 5. 670.16 (Nota hipocrática de enorme importancia, pues se establece una abierta oposición entre los cuerpos que han hecho ejercicios gimnásticos y los no sometidos a los mismos).

${ }^{48}$ Lo relevante aquí es el adverbio è $\xi a \pi i ́ v \eta \varsigma$ (exapínēs), "de repente, de pronto", vocablo ya homérico, pero relativamente poco usado hasta los tratados médicos. Lo entenderemos mejor dando unas cifras: usos hasta fines del siglo $\mathrm{V}, 133$; en el $\mathrm{CH}$, 88; es decir, el $66 \%$ de los empleos es de los médicos. Los autores hipocráticos, siempre atentos a las circunstancias temporales, reflejan con cuidado cuándo y cómo se presenta la enfermedad, el sudor, un dolor, una hinchazón, etc, o cuándo y cómo se ha realizado determinada acción, como es el caso que comentamos.

${ }^{49}$ Para la fusión de la carne, véase nota 44. Que tal fusión es causada por el ejercicio (pónos), lo encontramos en Vict. 2. 58, 59 y 62.

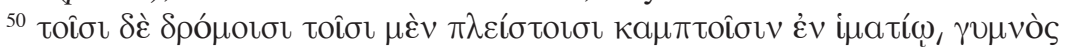

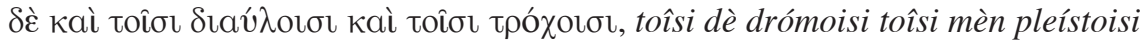
kamptô̂sin en himatíôi, gymnòs dè kaì tô̂si diaúloisi kaì tô̂si tróchoisi. La precisión

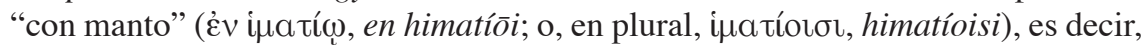
recubierto de un manto, la tenemos 6 veces en Vict. Concretamente, en 2. 63. 6. 578.15, se indica que las carreras (drómoi) con manto son buenas para varios tipos

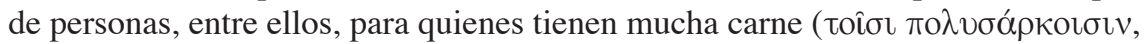

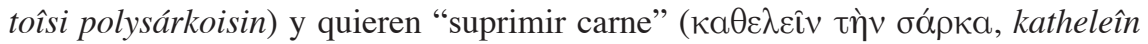
tēn sárka).

El adjetivo "desnudo", merece un comentario especial. Efectivamente,

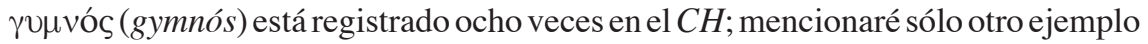
que tiene que ver con los ejercicios gimnásticos. Dentro de las recomendaciones dadas a quienes quieren adelgazar leemos: “Además, hacer una sola comida, no bañarse, dormir en lecho duro y pasear desnudo ( $\gamma \cup \mu \nu$ òv $\pi \varepsilon \rho \imath \pi a \tau \varepsilon ́ \varepsilon \iota v$, gymnòn peripatéein) tanto como se pueda", Salubr. 4. 6.76.14.

De enorme relevancia es el término gymnós dentro del mundo deportivo griego, donde la generalización del desnudo tuvo lugar en el siglo V. Según algunos testimonios literarios, una innovación típica de los griegos fue practicar ciertos deportes con el cuerpo desnudo: Tucídides, 1. 6.5, y Platón, $R$.. 452 c-d, nos informan sobre este punto. Nos dice el historiador que los lacedemonios fueron 
lucha con la punta de las manos y el combate contra el saco son más convenientes $^{51}$; y los paseos de después de los ejercicios gimnásticos,

los primeros en practicar ejercicios físicos y en frotarse con grasa después de la gimnasia, desnudándose en público; antiguamente, los atletas luchaban, incluso en

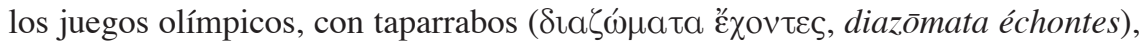
y todavía, en sus días, no habían pasado muchos años desde que habían dejado de hacerlo; refiriéndose a su propia época, nos dice que había algunos bárbaros, sobre todo asiáticos, entre los cuales se daban competiciones de pugilato y lucha realizadas con taparrabos; con ello, añade, se puede demostrar que los antiguos griegos tenían muchas costumbres semejantes a las propias de los bárbaros de aquellos momentos. Por su lado, Platón, hablando de que la costumbre de presentarse desnudos ante los demás había sido algo vergonzoso y ridículo para los griegos hasta hacía poco, criterio que seguía existiendo entre los bárbaros, insiste en que fueron los cretenses, y, a continuación, los lacedemonios los primeros en hacer uso de los gimnasios, demostrándoles la experiencia que era mejor desnudarse que cubrir todas las partes del cuerpo, con lo que se disipó la noción de ridículo y prevaleció el sentido de la conveniencia. No obstante hay un punto de socarronería socrática cuando se propugna que las mujeres sean educadas en todo como los hombres, y, entonces, se formula la pregunta de si tendrían que acudir completamente desnudas a ejercitarse en las palestras junto con los hombres, y, precisamente, no sólo las jóvenes, sino también las viejas, siguiendo el modelo de los ancianos que seguían acudiendo a los gimnasios a pesar de estar arrugados y carentes de todo atractivo.

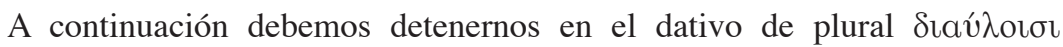

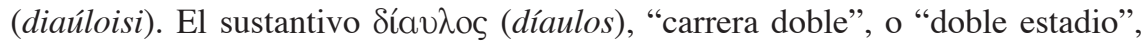
aparece 4 veces en el $\mathrm{CH}$, siempre en Vict. y en el mismo caso que hemos visto: I 35; II 63; III 68 y 78. Surge el vocablo en el siglo V: lo hallamos en Esquilo (1), Píndaro (2), Sófocles (1), Eurípides (5) y Aristófanes (1). Los estudiosos parten del término simple, aù $\lambda$ ó (aulós), "tubo, flauta", y, por analogía, cada una de las dos partes alargadas del estadio, visto como un tubo o foso alargado. Conviene recordar que en Grecia se usaban varios tipos de estadio como medida y como lugar para ejercitar la carrera. Así, el estadio de Delfos tiene 177,6 metros de largo, pues coincide con la medida ateniense; en cambio, el de Olimpia es de 192,27 metros (estadio olímpico); y el de Corinto (juegos Ístmicos), de 181,16 metros. Los autores no suelen indicar de qué estadio se trata. Así sucede en los tratados hipocráticos. Téngase en cuenta, además, que en época helenística se utilizó el estadio ptolemaico, equivalente a 210 metros; posteriormente, el estadio romano medía 185 metros.

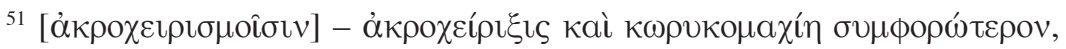
[akrocheirismoîsin]-akrocheírixis kaì kōrykomachie symphorōteron. El sustantivo

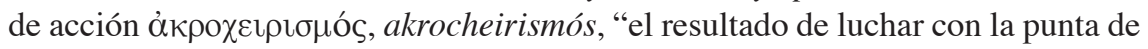


Un pasaje importante para el estudio de los ejercicios físicos

muchos, y también los de madrugada y los de después de la cena. El ejercicio de la voz es oportuno, pues, produciendo evacuación de lo húmedo, aligera la carne. Conviene quedarse sin desayuno. Usar esas normas diez días. Después, añadir la mitad del alimento suprimido durante seis días, y producir un vómito, y, después del vómito, incrementar el alimento hasta cuatro días. Y cuando pasen diez días después del vómito,

las manos" o "con el extremo de los brazos", lo tenemos 3 veces en el $\mathrm{CH}$, todos en Vict. (En este pasaje, Joly secluye ese término, siguiendo a otros editores). Es una innovación hipocrática; lo leemos, después, en Galeno (3), Luciano (1), Aspasio (1), Temistio (1), Oribasio (3), Aecio (1), Pablo de Egina (1), etc.

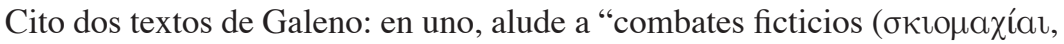
skiomachíai, o luchas contra la propia sombra), luchas con la punta de las manos (akrocheirismoí) y ejercicio gimnástico mediante el saco y la pelota pequeña", 6.144.2. En otro, afirma: "paseo y carrera son ejercicios gimnásticos propios de las piernas; y luchas con la punta de las manos y combates ficticios, de los

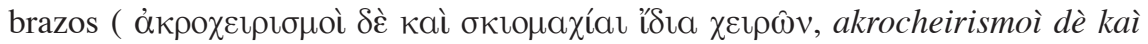
skiomachíai ídia cheirôn)", 6.146.14.

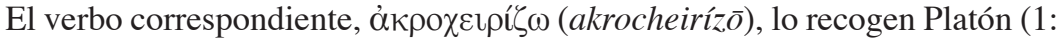
en Alcibiades 1.107 e: pone al pedotriba como experto en tal actividad), Aristóteles (1), Posidonio (2), Galeno (1), Luciano (1), Filóstrato (2), Ateneo (1), Aspasio (1), Olimpiodoro (1), Miguel Pselo (3), Eustacio (1), etc.

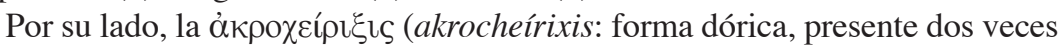

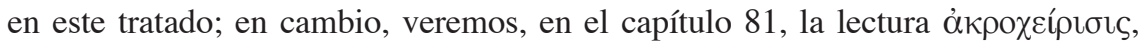
akrocheírisis, propia del jonio usado normalmente por los médicos) es la "acción de luchar con las puntas de las manos"; la encontramos tres veces en el $\mathrm{CH}$. Para entender bien el sentido, conviene dividir el término en ö́ $\rho о \varsigma$ (ákros), "elevado,

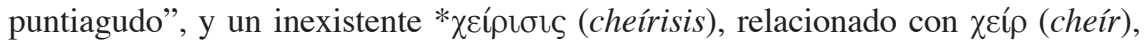
"brazo" o "mano". En Vict. 2. 64. 6. 580.16 se nos dice: "La lucha con las puntas

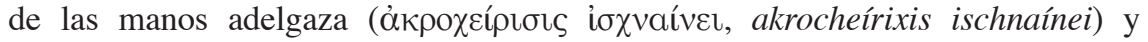
arrastra las carnes hacia arriba, y la lucha con el saco y el movimiento de brazos

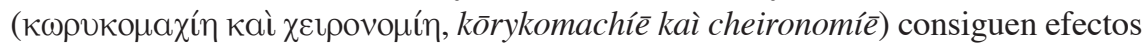
semejantes".

El sustantivo kōrykomachíe, "acción de luchar contra el saco de cuero", lo hallamos 3 veces en el $\mathrm{CH}$, y sólo aquí dentro de la literatura griega; todas ellas en

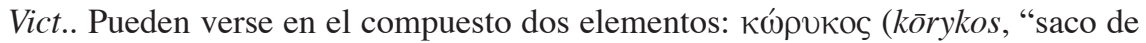
cuero", que lo leemos ya en la Odisea, 5.267, como receptáculo para provisiones, por ejemplo; el término pasó luego a la literatura posterior (Filóstrato, Luciano) y servía para denominar un saco relleno, que, colgado, resultaba apropiado para ser golpeado) y $\mu$ axín, machíe ("lucha”). 
apórtese todo el alimento suprimido. Que siga con los ejercicios y paseos, y estará sano. Tal naturaleza necesita más ejercicio que alimento ${ }^{52}$.

$79^{53}$. Algunos también experimentan lo siguiente. Su alimento es evacuado húmedo, sin digerir, no por enfermedad, como la lientería, pero no produce ninguna molestia. Sufren eso, sobre todo, cuantos vientres son fríos y húmedos. Pues por la frialdad, no digiere, y, por la humedad, evacua; por tanto, el cuerpo se consume, por no recibir el alimento conveniente, $\mathrm{y}$ las cavidades se corrompen, y caen en enfermedades. Pero es preciso prever. Le conviene a ése suprimir de los alimentos la tercera parte. Sean sus alimentos panes de harina gorda, sin levadura, cocidos en horno de campo o en cenizas, mojados calientes en vino seco. Y de los pescados, lomos y colas, pues las cabezas y el bajo vientre son bastante húmedos; unos, cocidos en salmuera, y otros, asados con vinagre. $\mathrm{Y}$ las carnes conservadas en sal y vinagre, y carnes de perro asadas. Y de paloma torcaz $\mathrm{y}$ de aves parecidas, cocidas o asadas. $\mathrm{Y}$ hortalizas, lo menos posible. $\mathrm{Y}$ vino tinto bastante puro y seco. Y los paseos de después de la cena, muchos, y también los de madrugada, y, después del paseo, que se acueste. Y carreras de fondo, según un incremento progresivo. Y haya mucha fricción y lucha corta, tanto con aceite como en el polvo ${ }^{54}$, para que, calentándose la carne,

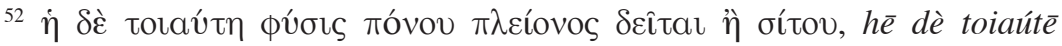
phýsis pónou pleíonos deîtai e étou. En este ejemplo el sustantivo фúous (phýsis: "naturaleza", concepto de extraordinaria importancia en la filosofía presocrática y entre los hipocráticos, que abarca, no sólo la naturaleza como realidad física general, sino también la condición particular de un grupo e incluso de un individuo) alude quizá no sólo a la naturaleza del ser humano descrito en el último capítulo, sino a la de los incluidos en los nueve (70-78) en que los alimentos dominan a los ejercicios.

${ }^{53}$ Según Joly, los seis capítulos siguientes (79-84) contienen ejemplos en que los ejercicios dominan a los alimentos. Se impone, pues, hacer menos ejercicios y llevar una dieta alimenticia adecuada. Una característica general es que en los casos expuestos hay problemas evidentes con las deposiciones, que salen húmedas, sin digerir, putrefactas, etc., señal inequívoca, para el médico, de la falta de equilibrio entre ejercicios y alimentos.

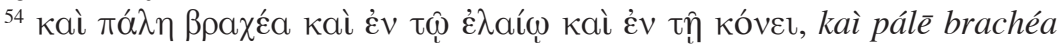
kaì en tôi elaíoi kaì en têi kónei. El sustantivo kónis, "polvo" lo hallamos 9 veces en el $\mathrm{CH}$ (7, en Vict.). La fórmula en kónei, "en el polvo, en medio del polvo", es propia sólo del tratado que revisamos. Se dice del "polvo" que es fresco (Vict. 2. 65 ); en verano, hacer ejercicios gimnásticos en el polvo produce un incremento 
se seque y atraiga, por revulsión ${ }^{55}$, lo húmedo procedente del vientre. Darse unciones conviene más que bañarse. Que se quede sin desayunar. Cuando trascurran siete días, añádase la mitad del alimento que se suprimió y provóquese un vómito. E increméntese el alimento hasta cuatro días. En la otra semana, que se suministre todo, $\mathrm{y}$, habiendo provocado un vómito, increméntese según la misma norma.

80. Y a algunos otros les sucede lo siguiente. La deposición sale sin digerir, y el cuerpo se consume al no aprovechar los alimentos; ésos, pasando el tiempo, caen en enfermedades. Sus cavidades son frías y secas. Por tanto, cuando no recurren a alimentos convenientes ni ejercicios gimnásticos, sufren esas cosas. A ése le conviene consumir panes de harina pura, cocidos al horno, y los pescados cocidos en salsa, y carnes porcinas cocidas y pies de cerdo bien cocidos y carnes grasas asadas, y, de los alimentos ácidos y salados, los que humedecen, y las salazones. Y vinos tintos suaves. Y uvas e higos entre los alimentos. Y es preciso también desayunar un poco. Y practiquen menos ejercicios gimnásticos, carreras de fondo, en progresión, y, por último, carreras, y, tras la carrera, lucha con aceite $^{56}$. Pero paseos, no muchos, después de los ejercicios gimnásticos. Y, tras la cena, sólo ponerse en pie. Pero, de madrugada, dar más paseos. Y darse un baño caliente. Y úsense también unciones. Y concédase más sueño y échese en lecho blando. Y es preciso también tener algún contacto venéreo. De los alimentos, suprimir la tercera parte; y, en diez días, volverlo a los alimentos.

notable, pues, al refrescar el cuerpo, impide que se caliente en exceso (Vict. 2. 65); en verano, se recomienda la "lucha en el polvo" (têi te pálēi en kónei) para evitar todo lo posible el calentamiento en exceso (Vict. 3. 68).

${ }^{55}$ Recordemos lo dicho en nota 32. Precisemos que, en este caso, ha sido la actividad gimnástica la que ha favorecido la antíspasis.

${ }^{56}$ El reparto es como sigue: ejercicios gimnásticos-carreras de fondo en aumento progresivo-además, carreras-, y, tras la carrera, lucha con aceite. De este pasaje pueden extraerse algunas conclusiones: los ejercicios gimnásticos, pues, cubren todas las demás actividades físicas; las carreras de fondo, ya explicadas en nota 42, tendrían un incremento controlado por algún médico o auxiliar (o, quizá, el propio paciente); después vendrían las tróchoi, carreras en general, que podríamos llamar "libres", para diferenciarlas de las de fondo; luego, el término genérico drómon, que recoge y abarca tanto las de fondo como las libres; finalmente, la lucha con aceite. 
81. Y hay algunos cuya deposición sale húmeda y corrompida; los cuales, por lo demás, están sanos y hacen ejercicios gimnásticos; y no les produce dolor. Pero algunos se alejan de sus asuntos. Y, pasando el tiempo, el vientre atrae las carnes con su calor y produce molestia; se alejan de los alimentos, y el vientre se ulcera y ya resulta difícil componerlo. Pero es preciso prever antes, sabiendo que el vientre está caliente y húmedo más allá de lo normal y que se produce un exceso de molestias inconvenientes. Con dieta, por tanto, es menester refrescarlo y secarlo. Y, en primer lugar, es preciso suprimir la mitad de los ejercicios gimnásticos, y, de los alimentos, la tercera parte. Consumir pan de cebada, amasado de antemano, de harina gorda, los pescados muy secos, cocidos, ni grasos ni salados; consúmanse también asados. Y carnes, las de ave: cocidas las de paloma torcaz y paloma; y las de perdices y gallinas, cocidas, sin condimentos; las de liebre, cocidas en agua; y las legumbres silvestres, cuantas son refrescantes, y las acelgas cocidas con vinagre. Y vino tinto seco. Y ejercicios gimnásticos, carreras rápidas; pero la fricción que no sea mucha, sino poca; y lucha, no ${ }^{57}$. Ahora bien, lucha con la punta de las manos, movimiento de brazos, combate contra el saco y lucha en el polvo son convenientes, pero no muchos ${ }^{58}$. Que practique los paseos, incluso después del gimnasio, suficientes en proporción a la fatiga, y, después de cenar, muchísimos, en proporción a los alimentos, y, al alba, de modo mesurado

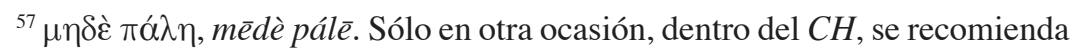
no practicar la lucha, ni la fricción ni la lucha en el polvo. Vict. 4. 89. 6. 648.14.

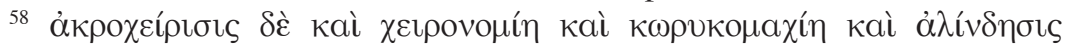

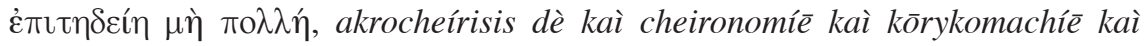
alíndēsis epitēdeié mē pollē. La cheironomiée, presente dos veces en el $\mathrm{CH}$ (sólo en Vict.), donde es una innovación, se interpreta como "movimiento de manos

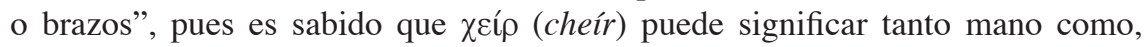
por extensión, brazo. Posteriormente la registran, entre otros, Rufo (1), Galeno (1), Oribasio (4), etc. Por su interés recogeré un pasaje de cada uno de estos tres médicos: "los movimientos de brazos, lanzamientos del saco de cuero y ejercicios pugilísticos", Sobre la satiriasis y gonorrea, 34.3; "movimiento de brazos, luchas con las puntas de las manos, lanzamientos de disco, uso de halteres y todos cuantos ejercicios gimnásticos se hacen, en tierra, en la palestra", 6.325.1; "el movimiento de brazos está entre la danza y la lucha ficticia", 6.30.1. Por ejemplos como éste último se ha interpretado el término como una especie de "lucha contra la propia sombra", es decir, contra un contrincante imaginario; referido, quizá, a un modo de entrenarse. En autores tardíos, el vocablo equivale a "juego de manos" y se aplica a la pantomima. 
Un pasaje importante para el estudio de los ejercicios físicos

en relación a su estado ${ }^{59}$. Que se dé un baño tibio y en reposo. Habiendo seguido este régimen durante diez días, añádase la mitad del alimento y la tercera parte de los ejercicios. Y provóquese un vómito después de alimentos secos y astringentes, y que no pase el tiempo con el alimento dentro, sino que vomite lo más rápido posible ${ }^{60}$. Después del vómito, incremente, hasta cuatro días, el alimento, la bebida y el ejercicio, distribuyéndolos. Cuando pase una decena, añádase el alimento restante y, de los ejercicios, en cantidad bastante insuficiente con relación al alimento; $\mathrm{y}$, tras provocarse un vómito, aumente paulatinamente, conforme queda escrito. Durante ese tiempo conviene hacer una sola comida ${ }^{61}$, hasta que se restablezca.

82. A algunos otros se les produce una deposición seca y quemada, y la boca seca; y, pasando el tiempo, también se les pone amarga, y el vientre se detiene y también la orina. Pues cuando el intestino no tiene humedad,

${ }^{59}$ Son de capital importancia las recomendaciones dadas al médico para que actúe de acuerdo con cada paciente, teniendo en cuenta que los ejercicios físicos sean suficientes con respecto a la fatiga (o ejercicio: pónon) y en

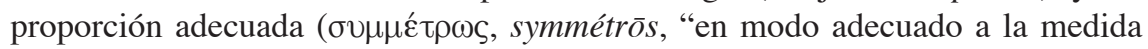
o proporción”) al estado (o forma) físico ("̌̌ıv, héxin). En casos así, podríamos hablar de prescripciones propias de una medicina personalizada, adaptada a las necesidades de cada paciente.

El adverbio symmétrōs es una innovación del $\mathrm{CH}$, donde lo encontramos 5 veces. En el siglo IV lo emplean, entre otros, Aristóteles (11), Teofrasto (3) y Epicuro (2).

Por su lado, ๕̌łıৎ (héxis: 22 en $\mathrm{CH}$ ) hace referencia a la forma física. Los

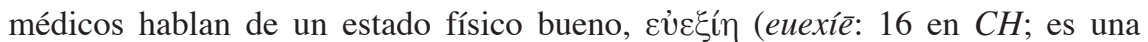
innovación hipocrática compartida con un fragmento de Eurípides (Fr. 201.1); fue bastante empleada en escritores posteriores; Galeno, por ejemplo, la recoge

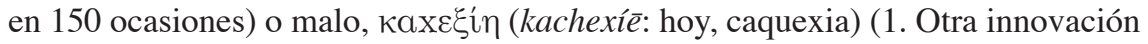
hipocrática, algo menos usada que $\varepsilon \dot{v} \varepsilon \xi i ́ \eta$ (euexíe en la literatura posterior; la emplean, entre otros, Jenofonte, en 8 ocasiones, y Galeno, en 31).

${ }^{60} \mathrm{Si}$ aquí se recomienda que el paciente no tenga los alimentos dentro de sí por mucho tiempo, en el capítulo siguiente encontramos la prescripción contraria.

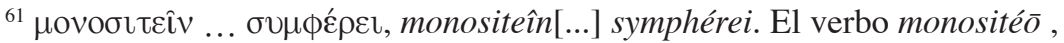
“comer sólo una vez" al día, es una innovación hipocrática (13). También lo es el sustantivo correspondiente, monositié (7). En el siglo IV sólo utilizan ese verbo, Jenofonte (2), Aristóteles (1) y el cómico Alexis (1). Mucho después, registramos ambos términos en Galeno (13 y 11 secuencias, respectivamente). 
hinchándose en torno al desecho, tapona las salidas, produce dolor y la fiebre ataca; y todo lo que coma o beba, lo vomita. Finalmente, vomita incluso excremento. Ése no puede vivir, cuando llega hasta ese punto. Pero es preciso prever sabiendo que la persona está dominada por una sequedad caliente. Por tanto, es preciso que siga una dieta con pan de cebada, amasado de antemano, humedecido, y pan de trigo sarraceno fermentado en jugo de salvado; y que consuma legumbres, salvo las ácidas y secas, cocidas. Y de los pescados, los muy ligeros, cocidos. Y también cabezas de pescados y langostas. Y mejillones, erizos y cangrejos y caldo de mariscos con concha, y esos mismos mariscos, muy húmedos. Y carnes: pies de cerdo delanteros, cocidos; y, también, las de cabrito, cordero y perrito, cocidas. [Y, de entre los pescados, los de río y lago, cocidos $]^{62}$. Vino suave, aguado.

Ejercicios, no muchos, ni rápidos, sino tranquilos todos. Practique paseos al alba, suficientes de acuerdo con su estado físico, y, después del ejercicio gimnástico, moderados con arreglo a su fatiga ${ }^{63}$. Después de la cena, no pasee. Disfrute de baños, sueños suaves y desayuno. Y un sueño, no largo, tras el desayuno. Consuma fruta que humedece, tras los alimentos; y garbanzos verdes, y, también, los secos, tras haberlos mojado en agua. Y, de los ejercicios, también ése suprima, desde el comienzo, la mitad de los anteriores. Y provoque un vómito después de alimentos dulces, grasos, salados y oleosos, pero que se retenga con los alimentos durante muchísimo tiempo con vistas a los vómitos. Después, que incremente el alimento hasta tres días, y que no permanezca sin desayunar. Y cuando pasen diez días, que de los ejercicios incremente progresivamente más. Y si se presenta plenitud después del alimento o desarreglo del vientre, que vomite. Y si no, sea tratado así durante el tiempo restante.

${ }^{62}$ Joly condena la frase contenida entre corchetes, entendiéndola como una glosa innecesaria.

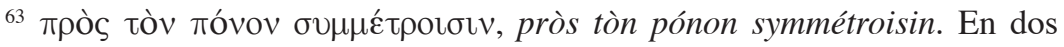
ocasiones muy próximas tenemos el giro preposicional formado por prós más acusativo: "de acuerdo con", "con arreglo a", "en proporción a". El hipocrático está acercándose a una atención personalizada de sus pacientes, o, al menos, de grupos que cumplen unas características generales. Es relevante el adjetivo sýmmetros, "adecuado, proporcionado, simétrico"; aparece en el siglo V: Esquilo (1), Eurípides (2), Demócrito (1). El $\mathrm{CH}$, uno de los primeros conjuntos literarios en emplearlo, lo registra 16 veces (6 en Vict.). 
83. Se produce también lo siguiente. Se presentan escalofríos después de los paseos de madrugada, y sienten pesadez de cabeza, tanta cuanto mayores que la medida son los paseos. Vaciándose el cuerpo, y también la cabeza, de la humedad, nota escalofríos y se siente pesado. Pasando el tiempo, llega a una fiebre que produce escalofríos. Pero es necesario que no avance hasta ese punto, sino que sea tratado antes de la siguiente manera. Nada más presentarse alguno de los indicios, tras ungirse y darse unas pocas fricciones, tome un desayuno mayor de lo acostumbrado, y beba bastante vino suave, y, después, tras el desayuno, eche un sueño suficiente. Hacia la tarde, tras haber practicado ejercicios gimnásticos ligeros ${ }^{64} \mathrm{y}$ haberse dado un baño caliente, cene lo acostumbrado. Y no dé paseos después de la cena, sino que pase el rato ${ }^{65}$. Al día siguiente, suprima de todos los ejercicios gimnásticos y paseos la tercera parte, y consuma sus alimentos, como estaba acostumbrado. Que se dé un baño templado y se unja con aceite, en el agua. Que pase el tiempo con sueños blandos ${ }^{66}$, y, en cinco días, incremente poco a poco los ejercicios.

84. Hay algunos que tienen escalofríos después de los ejercicios gimnásticos, y cuando se desvisten, hasta que hacen esfuerzos. Y cuando se enfría, siente de nuevo escalofríos, y un rechinamiento (sc. de dientes) domina al cuerpo. Y está somnoliento, y, cuando se despierta, bosteza muchas veces. Y, después del sueño, tiene párpados pesados. Y pasando el tiempo también se producen fiebres fuertes y delira. Por tanto, es necesario precaverse y no llegar a eso, sino que sea tratado como sigue. En primer

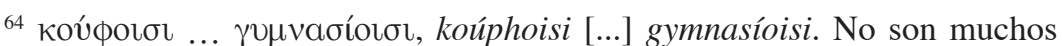
los calificativos que recibe gymnásion (el sustantivo lo hemos estudiado, especialmente, en nota 16): "más", "menos", "todos", "todos los demás", "tales", "acostumbrados" (véase Vict. 3. 70, en nota 16), "inoportunos" ( ákaíp $\omega v$, akaírōn. Epid. 1. 4. 2. 2. 608.9). Por otro lado, Vict. ofrece todos los ejemplos (3) en que aparece el adjetivo kouphós como nota indicadora de calidad: 3. 70, véase nota $18 ; 3.72$, donde los ejercicios gimnásticos son descritos como "ligeros y con incrementos"; $y$, ahora, en el texto que comentamos.

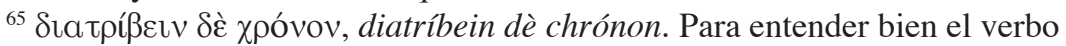
diatríbo, que, entre sus valores, tiene los de "entretenerse", "demorarse", acúdase al sustantivo diatribe $\bar{e}$, explicado en nota 46.

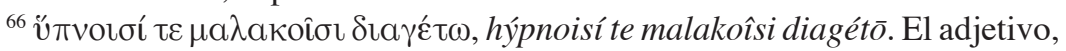
en plural, malakoí, "blandos", debe entenderse como calificativo del lugar donde se descansa. 
lugar, de los ejercicios gimnásticos, suprímalos todos o la mitad. Y consuma todos los alimentos bastante húmedos y bastante fríos, y bebidas bastante suaves y bastante aguadas. Y cuando pasen cinco días, que añada una tercera parte de los ejercicios que se suprimieron. Y consuma los mismos alimentos. Por otra parte, al quinto día, añada la mitad de los ejercicios restantes. Y, a su vez, en el quinto día tras eso, reanude todos los ejercicios, pero bastante más ligeros y menos numerosos, para que el exceso no se produzca de nuevo.

$85^{67}$. Pues en quienes experimentan esos signos, los ejercicios son más fuertes que los alimentos ${ }^{68}$. Por tanto, es preciso equilibrarlos ${ }^{69}$. Algunos no los experimentan todos, sino unos, sí, otros, no. En todos esos signos, los ejercicios dominan a los alimentos, y el tratamiento es el mismo. Les conviene a ésos darse baños calientes, dormir con blandura, embriagarse una sola vez o dos, pero no hasta el exceso, y tener relación venérea ${ }^{70}$, cuando hayan bebido un poco; relajarse en cuanto a los ejercicios, salvo en los paseos $^{71}$.

${ }^{67}$ Este capítulo contiene una conclusión parcial, referida solamente a los ejemplos en que los ejercicios prevalecen sobre los alimentos.

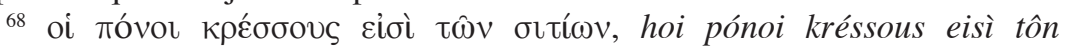
sitíōn. Entiéndase el comparativo kréssous con su valor propio: "más fuerte, más poderoso", construido con segundo término de la comparación : "que los alimentos". Tal comparativo corresponde a una importante familia de palabras en la que figura el verbo kratéo, "ser el más fuerte, tener el poder, dominar" (Cf. nota 10). Lo encontramos también unas líneas más abajo, cuando leemos que "los ejercicios dominan a los alimentos".

En este caso, el hipocrático aplica al terreno médico conceptos procedentes del terreno militar y político. No es bueno que un elemento (alimentos, ejercicios) domine sobre el otro; el médico ha de conseguir equilibrarlos, a fin de conseguir la salud del paciente.

${ }^{69}$ Es la primera aparición en griego del verbo ảví $\sigma \alpha ́ \zeta \omega$ (anisázō), "equilibrar", "igualar", formado sobre el adjetivo ǐoos (ísos), "igual, equivalente".

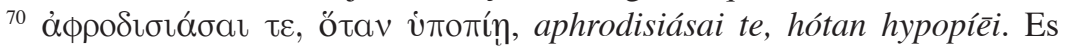
relevante la recomendación de beber con moderación, no mucho, antes de realizar el acto sexual. Es la única aparición hipocrática de hypopínō , "beber un poco", verbo que encontramos ya a fines del VI en Anacreonte.

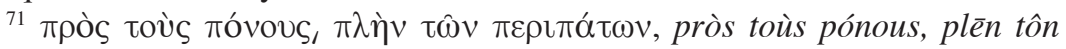
peripátōn. Un buen ejemplo que nos indica expresamente que los paseos (perípatoi) son ejercicios (pónoi). 
Un pasaje importante para el estudio de los ejercicios físicos

\section{Bibliografía selecta}

\section{a) Ediciones y traducciones}

HiPPOCRATE. Du RÉGIME (1984), edición, traducción y comentario de Joly, R., Berlín: Corpus Medicorum Graecorum, 1.2.4, (bilingüe: griegofrancesa). (Es la edición que sigo).

HIPPOCRATE. DU RÉGIME (1967), edición, traducción y comentario de Joly,

R., París: Collection des universités de France (bilingüe: griegofrancesa).

HIPPOCRATES. 3 (1967, reimpresión de 1931¹), edición, traducción y notas de Jones, W. H. S., Londres-Cambridge (Massachusetts): Loeb, 224447 (bilingüe: griego-inglesa).

OEUVRES COMPLÈTES D 'HiPPOCRATE. 1-10 (1961, reimpresión de París: 1839$\left.1861^{1}\right)$, edición, traducción y notas de Littré, E., Amsterdam: Hakkert (6: 466-563) (bilingüe: griego-francesa).

TRATADOS hiPOCRÁtICOS. 3 (1986), Madrid: Gredos,19-116 (traducción española y notas).

\section{b) Índice y Concordancia}

INDEX HiPPOCRATICUS. (1986), Kühn, J. H. - Fleischer, U. (eds.), Hamburgo:

Vandenhoeck\& Ruprecht (Es el mejor instrumento léxico sobre los tratados hipocráticos: en numerosas ocasiones distingue varios significados dentro de un término y examina diversas lecturas de los manuscritos).

CONCORDANCE DES OEUVRES HIPPOCRATIQUES. (1986), Maloney G.- Frohn, W.(eds.), Hildesheim:Olms (Es útil, especialmente para el número de apariciones de las palabras).

\section{c) Bibliografía auxiliar}

Angelopoulou, N. (2000), "Hippocrates on Health and Exercise", Niképhoros 13: 141-52.

Christesen, P. (2002), "On the meaning of gymnázo", Niképhoros 15: 7-37. 
Chryssafis, E. (1937), "La médecine sportive chez Hippocrate", en Mallwitz, A. (ed.), Verhandlungen II internationaler SportärzteKongress (Berlín, 1936). Leipzig: G. Thieme, 229-31.

DaremberG, Ch. - Saglio, E. (1969 reimpresión; París, 1877-19191), Dictionnaire des antiquités grecques et romaines, d'après les textes et les monuments. Graz: Akademische Druck (Útil todavía en numerosas entradas).

Gallego Pérez, M. T. (1999), "Gymnós y derivados en el Corpus Hippocraticum”, en Garofalo, I.- Lami, A. - Manetti, D.- Roselli, A. (eds.), Aspetti della terapia nel Corpus Hippocraticum. Atti del IX Colloque international hippocratique (Pisa, 25-29 septiembre 1996). Florencia: Olschki, 314-326.

García Romero, F. (1992), "Ejercicio físico y deporte en el Corpus hipocrático", en López Férez, J. A. (ed.), Tratados hipocráticos (Estudios acerca de su contenido, forma e influencia). Actas del VII Colloque international hippocratique (Madrid, 24-29 septiembre 1990). Madrid: UNED, 225-233.

LóPEZ Férez, J. A. (1988), "La colección hipocrática", en López Férez, J. A. (ed.), Historia de la literatura griega. Madrid: Cátedra, 617-649.

Mering, W. (1937), Die Anschauungen des Hippokrates über Gymnastik und Massage (Tesis). Munich.

DER NEUE PAULY (1996 ss.), Enkyklopädie der Antike. Stuttgart-Weimar: Metzler Verlag (Véanse, por ejemplo: (1998), "Gymnasion", 5: 20-7; (2001), "Sport", 11: 838-46; etc.).

NiKÉPHOROS (1983 ss.), Zeitschrift für Sport und Kultur im Altertum. Hildesheim: Weidmann (Muy útil, especialmente, los apéndices bibliográficos)

PAULYS REALENCYCLOPÄDIE DER CLASSISCHEN ALTERTUMSWISSENSCHAFT (1869 ss.), Stuttgart: J.B. Metzler (Véanse, por ejemplo, (1893), "Akrocheirismós", 1.1, 1197-8; (1899), "Cheironomía", 3.2, 2224-5; (1905), "Dromos", 1.2, 1716-20; (1912), "Gymnasium",7.2, 2004-6; (1912), "Gymnastik", 7.2, 2030-85; (1942), "Palaistra", 18.2, 247297; (1949), "Pale", 18.3, 82-9; etc.).

VISA, V.(1992), "L'image de l'athlète dans la Collection hippocratique", en Tratados hipocráticos...: 273-283. 
Un pasaje importante para el estudio de los ejercicios físicos

\section{d) Algunas abreviaturas internacionales de tratados del $\mathrm{CH}$, usadas en este trabajo.}

Acut.(Sp.) (de uictu acutorum. Spuria); Ä̈r. (de aëre, aquis, locis); Aff. (de affectionibus); Alim. (de alimento); Aph. (Aphorismi); Art. (de articulis); Coac. (Coacae praenotiones); Epid. (Epidemiarum libri); Flat. (de flatibus); Int. (de internis affectionibus); Genit. (de genitura); Loc. Hom. (de locis in homine); Morb. (de morbis); Mul.(de morbis mulierum); Nat. puer. (de natura pueri); Prorrh. (Prorrheticus); Salubr. (de uictu salubri); Vict. ( de uictu); VM (de uetere medicina). 